\title{
The Role of Extratropical Background Flow in Modulating the MJO Extratropical Response ${ }^{\mathscr{O}}$
}

\author{
CHENG ZHENG AND EDMUnd KAR-MAN CHANG \\ School of Marine and Atmospheric Sciences, Stony Brook University, State University of New York, Stony Brook, New York
}

(Manuscript received 20 September 2019, in final form 28 February 2020)

\begin{abstract}
The Madden-Julian oscillation (MJO) is the dominant mode of tropical intraseasonal variability. Many studies have found that the MJO, which acts as a tropical heating source, can excite Rossby waves that propagate into the midlatitude and modulate midlatitude circulation. The extratropical mean flow can modulate the MJO extratropical response. Rossby waves can grow or decay in different extratropical background flows, and the propagation of the Rossby waves also varies as the background flow acts as a waveguide. In this study, how extratropical mean flow modulates the MJO extratropical response is explored by using a nonlinear baroclinic primitive equation model. MJO-associated heating, as an external forcing of the model, is imposed into scenarios with different extratropical background flows. Different background flow modulates the generation and advection of the vorticity anomalies induced by the MJO, which determines the initial location and strength of the Rossby waves. The midlatitude waveguides can be different as the background flow changes. As the propagation of Rossby waves follows the waveguides, the background flow determines whether the Rossby waves are trapped in the Pacific Ocean region or can propagate to the north and to the east into North America. The experiments also show that the anomalies associated with the Rossby waves can extract energy from the midlatitude jet over the jet exit region and the southern flank of the jet. This further modulates the strength, location, and duration of the MJO extratropical response.
\end{abstract}

\section{Introduction}

The Madden-Julian oscillation (MJO), characterized by large-scale eastward-propagating tropical convection from the Indian Ocean through the "Maritime Continent" to the western Pacific Ocean, is the dominant mode of intraseasonal tropical variability (Madden and Julian 1971, 1972, 1994). The MJO-associated large-scale convective anomalies are mainly over the region from Indian Ocean to western Pacific. Once the MJO reaches the date line, convection subsides and the disturbance is mainly confined to dynamical fields, which can circumnavigate the entire tropics (Waliser et al. 2009). The MJO also has impact on the circulation in the extratropics. As shown by many studies (e.g., Hoskins and Karoly 1981; Jin and Hoskins 1995; Sardeshmukh and Hoskins 1988), tropical diabatic

Supplemental information related to this paper is available at the Journals Online website: https://doi.org/10.1175/JCLI-D19-0708.1.

Corresponding author: Cheng Zheng, cheng.zheng.1@stonybrook.edu heating can excite Rossby waves that propagate into the extratropics. The MJO-associated eastward moving convection, which acts as a diabatic heating source, excites Rossby waves that propagate into the midlatitudes and modify midlatitude circulation (e.g., Matthews et al. 2004; Riddle et al. 2013; Seo and Son 2012). Thus, some important modes of climate variability, such as the North Atlantic Oscillation (e.g., Cassou 2008; Lin et al. 2009), the Arctic Oscillation (e.g., Flatau and Kim 2013; L'Heureux and Higgins 2008; Zhou and Miller 2005), and the Pacific-North America pattern (e.g., Mori and Watanabe 2008; Schreck et al. 2013), can be modulated by the MJO.

As Zheng and Chang (2019) pointed out, the MJO can also modulate midlatitude surface weather, such as surface air temperature, precipitation and extratropical cyclone activity (e.g., Zheng et al. 2018). Previous studies have found that the MJO has significant impact on surface air temperature at high latitudes (Vecchi and Bond 2004; Yoo et al. 2011), over Canada (Lin and Brunet 2009), the United States (Zhou et al. 2012; Hu et al. 2019), and Asia (Seo et al. 2016; Song and Wu 2019). The MJO 
also induces precipitation anomalies over North America (e.g., Baxter et al. 2014; Becker et al. 2011; Donald et al. 2006; Lin et al. 2010; Zhou et al. 2012). The MJO also significantly modulates extratropical cyclone activity, which accounts for much of the high-impact and extreme weather during winter (e.g., Kunkel et al. 2012; Ma and Chang 2017). The MJO modulation on extratropical cyclone activity has been found over much of the midlatitude Northern Hemisphere, including the Pacific, North America, North Atlantic, and northern Europe (Deng and Jiang 2011; Lee and Lim 2012; Grise et al. 2013; Guo et al. 2017). These MJO impacts on surface weather can be explained by the Rossby wave train induced by the MJO. The MJO-induced Rossby waves are associated with enhanced or suppressed upperlevel zonal wind, which modulates the extratropical cyclone activity and precipitation, and induce warm or cold advection, to give rise to the surface temperature anomalies (Zheng et al. 2018). Thus, the upper-level Rossby wave train, as it connects the MJO and extratropical surface weather anomalies, is very important. In addition, the strongest $\mathrm{MJO}$ extratropical impact is induced by the MJO with a 1-2-week lag time (e.g., Cassou 2008; Lin et al. 2009; Zheng et al. 2018). Since the MJO can be predicted out to 3-4 weeks (e.g., Kim et al. 2014; Lim et al. 2018; Vitart 2017; Xiang et al. 2015; Kim et al. 2018), the MJO-forced extratropical response can be very useful for subseasonal predictions (e.g., Xiang et al. 2019; Tian et al. 2017; DelSole et al. 2017; Tseng et al. 2018). Therefore, understanding what factors modulate the MJO-induced Rossby waves can help to improve subseasonal prediction.

The MJO extratropical response can be modulated by multiple factors. As the MJO provides the source of the Rossby waves, if the MJO has different initiation or decaying location, propagation speed, or lifetime, then the extratropical response can be different. For example, slow-propagating MJO events are found to have a stronger response over the North Atlantic than fast-propagating events (Yadav and Straus 2017). The strongest extratropical response is usually generated by phases 2 and 3 or 6 and 7 in model experiments (e.g., Seo et al. 2016; Tseng et al. 2019). Lin and Brunet (2018) showed that the mirroring phase of the MJO (similar distribution of the heating but with opposite sign) produces an asymmetrical extratropical response. By using an idealized general circulation model (GCM), Zheng and Chang (2019) showed that, to excite strong response in the extratropics, the MJO needs to go through a series of specific phases (phases 1-3 and 5-7; see section 2a for definition of MJO phases). If the MJO decays in phase 4 or 8 , the extratropical response lasts for a long period, whereas if the MJO propagates into phase 5 or 1 , the extratropical signal decays quickly or even the sign of the extratropical response reverses.

Other than the MJO itself, the midlatitude background flow, which determines how Rossby waves propagate and evolve, can also significantly modulate the MJO extratropical impact. As shown by Goss and Feldstein (2015) and by Lin and Brunet (2018) using idealized modeling studies, if the initial background flow is different, the same MJO-like tropical heating can generate different extratropical responses. Henderson et al. (2017), who utilized 10 models from phase 5 of the Coupled Model Intercomparison Project (CMIP5) and a linear baroclinic model, found that models with zonally extended Pacific subtropical jet show an eastward shift in the MJO teleconnection patterns. The eastward shift is primarily due to errors in the model basic state rather than the MJO heating. The MJO-induced Rossby waves tend to propagate along a zonal pathway if the waveguide is more zonally oriented due to the mean state of the model. Lukens et al. (2017) showed that the MJO-induced Rossby waves are trapped over the regions where the jet is strong. The Rossby waves can only start to propagate into the extratropics once they reach the jet exit region. The Rossby waves can also be amplified by stationary eddy advection over the jet exit region.

In this study, we will mainly investigate three aspects of how the extratropical basic state modulates the MJO extratropical response. First, we will explore whether the MJO-induced Rossby waves are different in different extratropical basic states during the initial stage (a couple of days after the MJO heating is turned on). Following previous studies (Seo and Son 2012; Seo and Lee 2017), the Rossby wave source (RWS; Sardeshmukh and Hoskins 1988; Jin and Hoskins 1995) will be investigated. Besides the RWS, which has been intensively discussed in previous studies, we also investigate what factors can modulate the vorticity tendency. This will provide insights about the location and intensity of the Rossby waves during the initial stage. This is important as the initial location and amplitude of the Rossby waves can lead to different propagation and amplitude of the Rossby wave in the later stages. Second, we will explore how the extratropical basic state modulates the propagation of the MJO-induced Rossby waves. Similar to Henderson et al. (2017), the stationary wavenumber, also referred to as the midlatitude waveguide (Hoskins and Ambrizzi 1993; Ting and Sardeshmukh 1993), will be investigated. Third, we will explore how the extratropical basic states modulate the amplitude of the MJO extratropical response, which have not been a main focus in the previous studies related to MJO extratropical impact. As discussed in Simmons et al. (1983), barotropic energy exchange from the mean kinetic energy to eddy 
kinetic energy can happen in the jet exit region, which can amplify the MJO-induced Rossby waves. As the energy exchange is proportional to the gradient of the jet speed, different jet structures can lead to different energy exchange. We will investigate whether the barotropic energy exchange can modulate the amplitude of the MJO extratropical response. Our results will provide explanations about the differences of the amplitude of the MJO extratropical response in different basic states. These three aspects will be explored by using a nonlinear baroclinic primitive equation model. The extratropical basic states in this study, which are constructed based on the winter climatology and the first three EOFs of the $300-\mathrm{hPa}$ zonal wind in the reanalysis, are more close to the realistic basic states compared to previous studies (e.g., Henderson et al. 2017), which investigated how different extratropical basic states modulate the MJO extratropical response in GCMs. Goss and Feldstein (2015) and Lin and Brunet (2018) used different initial basic flow (initial conditions from snapshots in reanalysis; no modifications of model mean state) to test how the extratropical basic states modulate the MJO extratropical response. Our approach is different from those in these two previous studies, as we directly modify the model basic state (model climatology; see section 2). This approach can help us separate the mean state and extratropical response more easily and may provide more insights about the evolution of the MJO extratropical response in a dynamical perspective. In addition, as we directly specify the basic state by using EOFs of the zonal wind, instead of using snapshots in the reanalysis as the initial condition, the model experiments in this study provide more direct information about what variations in basic states lead to what variations in the MJO extratropical response.

The datasets used in the study, methods to construct different basic states and analyze the Rossby wave propagation and evolution, and the nonlinear baroclinic primitive equation model setup are described in section 2 . Section 3 describes the main features of the MJO extratropical response in the model experiments with different MJO heating imposed. Section 4 investigates how the basic state modifies the initial generation of the Rossby waves by the MJO. The propagation and evolution of the Rossby waves in the midlatitudes are described in section 5. Discussions and conclusions are provided in sections 6 and 7, respectively.

\section{Method}

\section{a. MJO index and reanalysis}

We make use of the real-time multivariate MJO (RMM) index (Wheeler and Hendon 2004) to define the MJO phases in this study. The RMM index, which is a commonly used MJO index, is based on multivariate EOF analysis of the combined fields of outgoing longwave radiation and 850 - and $200-\mathrm{hPa}$ zonal wind anomalies. The first two leading normalized principal components are referred to as RMM1 and RMM2. The eight-phase life cycle can be defined based on the sign and amplitude of RMM1 and RMM2.

This study uses European Centre for Medium-Range Weather Forecasts interim reanalysis (ERA-Interim; Dee et al. 2011) 6-hourly geopotential height at $300 \mathrm{hPa}$ on a $0.75^{\circ}$ by $0.75^{\circ}$ horizontal resolution grid from 1979 to 2016 to evaluate MJO-induced Rossby wave trains [following Zheng and Chang (2019)]. Monthly averaged divergence, vorticity, and temperature on pressure levels, as well as surface pressure, are used to construct the basic state of the model. Temperature tendency from diabatic processes, a forecast product from ERA-Interim, which represents diabatic heating, is initialized at 0000 and 1200 UTC each day and outputs over ranges of hour 3, 6, 9, and 12 at 60 model levels and on a $0.75^{\circ}$ by $0.75^{\circ}$ horizontal resolution grid. The MJOrelated diabatic heating imposed into the model is constructed from ERA-Interim temperature tendency data as discussed below.

\section{b. Nonlinear baroclinic primitive equation model and MJO-related heating}

A nonlinear baroclinic primitive equation model is used in this study, which is the same as the stationary wave model used in Zheng and Chang (2019). This model is a modified version of the dry idealized GCM used in Xia and Chang (2014), which is first introduced by Chang $(2006,2009)$. The model is based on the dynamical core of the Geophysical Fluid Dynamics Laboratory global spectral model (Held and Suarez 1994). We run the model with 20 evenly spaced sigma levels in the vertical and horizontal resolution of T42 $\left(\sim 2.8^{\circ}\right)$. The model has realistic orography, Rayleigh friction, and Newtonian cooling toward a radiative equilibrium temperature profile, as well as fourthorder diffusion. Following the approach in Yang and Chang (2006), the imposed basic state is maintained to be stationary by subtracting off the time tendency computed from an initial model time step. The model uses strong damping such that high-frequency synoptic-scale transients are absent, and only the large-scale, low-frequency response to tropical heating is simulated. Details of the model can be found in Zheng and Chang (2019). As discussed in Zheng and Chang (2019), this model is a useful tool to analyze the MJO extratropical response. This is because the MJO-excited Rossby waves are quasi-stationary (e.g., Zheng et al. 2018), and previous studies (e.g., Held et al. 2002; Wang and Ting 1999) have 
shown that the stationary wave model is a powerful diagnostic tool for understanding the maintenance of stationary planetary waves. Note that it is shown in Zheng and Chang (2019) that the MJO extratropical response in this model (also see Fig. 2c, described in more detail below) is very similar to that in the original version of the model (with synoptic transient; also see Fig. 2e in Zheng and Chang 2019), and the model has similar MJO extratropical response to that in the reanalysis. This gives us more confidence to use this model to study the role of the background flow on modulating the MJO extratropical response.

The MJO-heating imposed into the model is the RMM-associated heating calculated by regressing the temperature tendency anomaly data onto DecemberFebruary (DJF) RMM1 and RMM2. The regression fields over the entire tropics $\left(20^{\circ} \mathrm{S}-15^{\circ} \mathrm{N}\right)$ are used to construct the heating. Details can be found in Zheng and Chang (2019). The heating imposed into the model is constructed with the following equation:

$$
Q_{\mathrm{MJO}}=\mathrm{rmm} 1 \times Q_{\mathrm{RMM} 1}+\mathrm{rmm} 2 \times Q_{\mathrm{RMM} 2} .
$$

Here, $Q_{\mathrm{MJO}}$ is the heating imposed into the model, $Q_{\mathrm{RMM} 1}$ and $Q_{\mathrm{RMM} 2}$ are RMM1- and RMM2-associated heating calculated from the regression, and rmm1 and rmm2 can represent any observed or idealized evolution of the RMM indices. Two different sets of heating, which both have been described in Zheng and Chang (2019), are imposed into the model. One is REAL $\mathrm{MJO}$, which is the MJO heating constructed by using observed time series of the RMM indices for 37 winter seasons $(\mathrm{rmm} 1=\mathrm{RMM} 1$ and $\mathrm{rmm} 2=\mathrm{RMM} 2$; RMM1 and RMM2 represent the observed RMM indices). The evolution of this heating, which covers 37 winter seasons from 1979 to 2016, follows the actual evolution of the RMM indices. Thus, the propagation and amplitude of REAL_MJO heating should be very similar to the MJO heating in the real atmosphere. The extratropical response to this heating reflects how the models capture the MJO extratropical response when the imposed heating has similar temporal and spatial evolution as the MJO diabatic heating in the real atmosphere. The other heating is PHASE2_15 days, which is stationary RMM phase- 2 heating that is turned on at day 0 and turned off at day 15 in a model run with an amplitude of 1.5. The amplitude of the RMM index is defined as $\left(\mathrm{RMM}^{2}+\right.$ $\left.\mathrm{RMM} 2^{2}\right)^{1 / 2}$. RMM phase 2 is selected because phases 2 and 6 excite the strongest response with opposite signs in the model. As discussed in Zheng and Chang (2019), phases 1 and 3 induce similar extratropical response but with smaller amplitude when compared with phase 2 , the amplitude of extratropical response induced by phase- 4 and phase- 8 stationary heating is small, and the average propagation speed of the RMM index is about 5 days per phase [also see Wheeler and Hendon (2004)]. Thus, the extratropical response related to the stationary phase 2 heating, which lasts 15 days, can represent the extratropical response induced by a typical MJO event. Also, the location and strength of the extratropical response in different background flow scenario forced by RMM phase 2 heating are very similar to that with REAL_MJO heating (see section 3). Different heating imposed in different model experiments can be found in Table 1.

As discussed in Zheng and Chang (2019), there are some limitations with the experiment setup. The MJOinduced Rossby waves may give rise to precipitation in the extratropics, which can modulate the extratropical response, such as amplifying blocking events associated with the MJO (e.g., Henderson and Maloney 2018). These moist processes cannot be captured in our experiment as we are using a dry model. Extratropical circulations can also influence the initiation, strengthening, and propagation of the MJO (e.g., Adames et al. 2014; MacRitchie and Roundy 2016; Ray et al. 2009; Ray and Li 2013; Zhao et al. 2013). As the MJO heating is prescribed in the experiments, the influence on the MJO by the extratropical circulation cannot be investigated.

\section{c. Basic states in the model}

Following Zheng et al. (2018) and Zheng and Chang (2019), we focus on the wintertime MJO extratropical response. The model simulation with the climatology of DJF from 1979 to 2016 in ERA-Interim as the basic state serves as the control run of the experiments. To explore the MJO extratropical response with different background flow, different basic states are constructed from climatology and the leading EOFs of $300-\mathrm{hPa}$ zonal wind in ERA-Interim, as 300-hPa zonal wind is a good representation of wintertime extratropical jet and the MJO extratropical response is also analyzed on the $300-\mathrm{hPa}$ level. The EOF analysis is performed by using monthly $300-\mathrm{hPa}$ zonal wind in DJF from 1979 to 2016 over the Pacific $\left(0^{\circ}-90^{\circ} \mathrm{N}, 90^{\circ} \mathrm{E}-135^{\circ} \mathrm{W}\right.$; see Fig. 1), as it is a region that has large variability in the extratropical flow, and it is close to the MJO diabatic heating so that it has direct influence on MJO extratropical response. The patterns of the first three EOFs, which explain $30.72 \%, 16.33 \%$, and $12.33 \%$ of the variance of the monthly zonal wind at $300 \mathrm{hPa}$, respectively, are shown in Figs. 1a-c. Total variance of DJF $300-\mathrm{hPa}$ zonal wind on monthly time scale is shown in Fig. 1d. Note that the first three EOFs are distinguishable based on North's test (North et al. 1982). For positive EOF1, the zonal wind over the southern 
TABLE 1. Summary of experiments in this study.

\begin{tabular}{|c|c|c|c|}
\hline Expt & External forcing & Model basic state & Expt duration \\
\hline $\begin{array}{l}\text { REAL_MJO climatological } \\
\text { basic state }\end{array}$ & Realistic MJO heating & Climatological basic state & 37 winter seasons \\
\hline REAL_MJO EOF1 \pm & Realistic MJO heating & $\begin{array}{l} \pm 1 \text { std dev of the EOF1 (DJF 300-hPa zonal } \\
\text { wind over North Pacific)-associated } \\
\text { pattern superposed onto DJF climatology }\end{array}$ & 37 winter seasons \\
\hline REAL_MJO EOF2 \pm & Realistic MJO heating & $\begin{array}{l} \pm 1 \text { std dev of the EOF2 (DJF 300-hPa zonal } \\
\text { wind over North Pacific)-associated pattern } \\
\text { superposed onto DJF climatology }\end{array}$ & 37 winter seasons \\
\hline REAL_MJO EOF3 \pm & Realistic MJO heating & $\begin{array}{l} \pm 1 \text { std dev of the EOF3 (DJF 300-hPa zonal } \\
\text { wind over North Pacific)-associated pattern } \\
\text { superposed onto DJF climatology }\end{array}$ & 37 winter seasons \\
\hline $\begin{array}{l}\text { PHASE2_15days climatological } \\
\text { basic state }\end{array}$ & $\begin{array}{l}\text { Stationary RMM phase- } 2 \text { heating } \\
\text { from day } 0 \text { to day } 15\end{array}$ & Climatological basic state & 100 days \\
\hline PHASE2_15days EOF1 \pm & $\begin{array}{l}\text { Stationary RMM phase- } 2 \text { heating } \\
\text { from day } 0 \text { to day } 15\end{array}$ & $\begin{array}{l} \pm 1 \text { std dev of the EOF1 (DJF 300-hPa zonal } \\
\text { wind over North Pacific)-associated pattern } \\
\text { superposed onto DJF climatology }\end{array}$ & 100 days \\
\hline PHASE2_15days EOF2 \pm & $\begin{array}{l}\text { Stationary RMM phase- } 2 \text { heating } \\
\text { from day } 0 \text { to day } 15\end{array}$ & $\begin{array}{l} \pm 1 \text { std dev of the EOF2 (DJF 300-hPa zonal } \\
\text { wind over North Pacific)-associated pattern } \\
\text { superposed onto DJF climatology }\end{array}$ & 100 days \\
\hline PHASE2_15days EOF3 \pm & $\begin{array}{l}\text { Stationary RMM phase- } 2 \text { heating } \\
\text { from day } 0 \text { to day } 15\end{array}$ & $\begin{array}{l} \pm 1 \text { std dev of the EOF3 (DJF 300-hPa zonal } \\
\text { wind over North Pacific)-associated pattern } \\
\text { superposed onto DJF climatology }\end{array}$ & 100 days \\
\hline
\end{tabular}

flank of the Pacific jet and the jet exit region is enhanced, while the wind speed decreases in the northern flank of the jet. This features a jet extension in the southern part of the climatological jet. For positive EOF2, over the southern flank of the Pacific jet, the wind speed is enhanced. For negative EOF2, the wind speed decreases in the northern flank of the climatological jet and the jet exit region. This features a jet extension and northward tilt in the northern part of the jet for negative EOF2. For positive EOF3, the wind speed decreases in the jet core and increases in the flanks and east of the jet exit. This features a broadening of the jet. Six additional basic states are constructed with \pm 1 standard deviations of the three EOFs with following steps: 1) Reanalysis global temperature, vorticity, and divergence on pressure levels, as well as surface pressure, are regressed onto the EOF time series. 2) \pm 1 standard deviations of the EOF-associated temperature, vorticity, divergence, and surface pressure patterns (from the regression), are superposed onto the DJF climatology. 3) The data are then interpolated from the reanalysis grid onto the model grid and used as the basic state of the model simulations. In the 117 winter months during 19792016 , there are $22,22,21,22,21$, and 18 winter months exceeding one standard deviation of positive EOF1, negative EOF1, positive EOF2, negative EOF2, positive EOF3, and negative EOF3 respectively. Note that we have also run experiments with basic states constructed using \pm 2 standard deviations of the EOFs, and the main features of the extratropical response in \pm 2 standard deviation basic states are similar to those in the \pm 1 standard deviation experiments (the results for \pm 2 standard deviation basic states are not shown in the main figures). Different basic states imposed in different model experiments are shown in Table 1.

\section{d. Methods to analyze rossby wave propagation and evolution}

The RWS induced by the MJO is examined using the linear barotropic vorticity equation (Sardeshmukh and Hoskins 1988):

$$
\frac{\partial \zeta^{\prime}}{\partial t}=S^{\prime}-\overline{\mathbf{v}_{\psi}} \cdot \nabla \zeta^{\prime}-\mathbf{v}_{\psi}^{\prime} \cdot \nabla \bar{\zeta}+F^{\prime},
$$

where the overbar represents the background mean flow and the prime represents the perturbation, which is the total deviation from the background mean (note that as synoptic-scale waves are damped in the model, the perturbations are of time scales that are longer than synoptic time scale); $S^{\prime}$ denotes the RWS; $\mathbf{v}_{\psi}$ is the rotational velocity vector; $\zeta$ represents absolute vorticity; and $F^{\prime}$ is the frictional term. The second and third terms on the right-hand side (rhs) of Eq. (2) represent the vorticity tendency due to advection by the rotational wind. These two terms are related to the propagation of the Rossby waves, while the first term $S^{\prime}$ represents the source of the Rossby waves. The second and third terms on the rhs of Eq. (2) will be combined and named as the rotational 


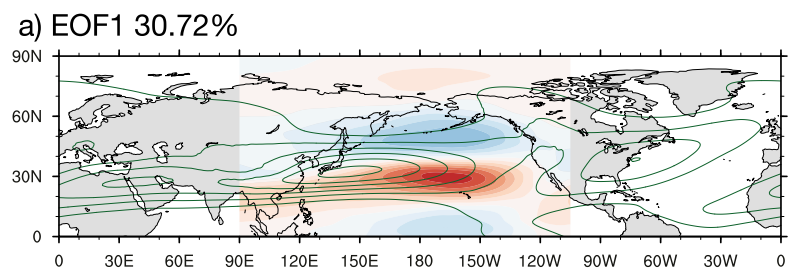

b) EOF2 $16.33 \%$

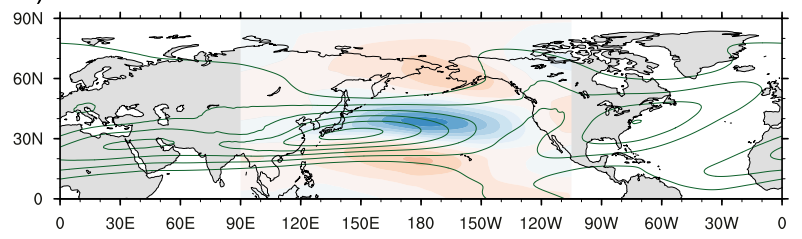

c) EOF3 $12.33 \%$

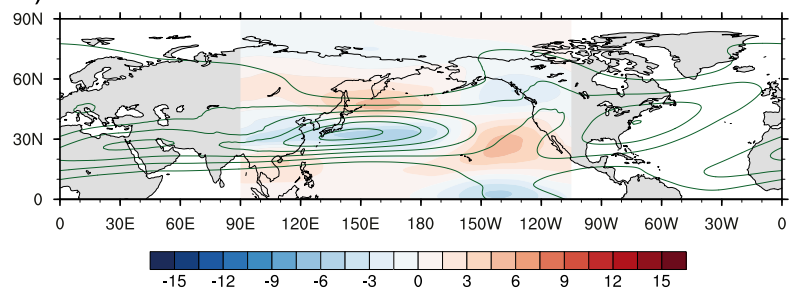

d) variance

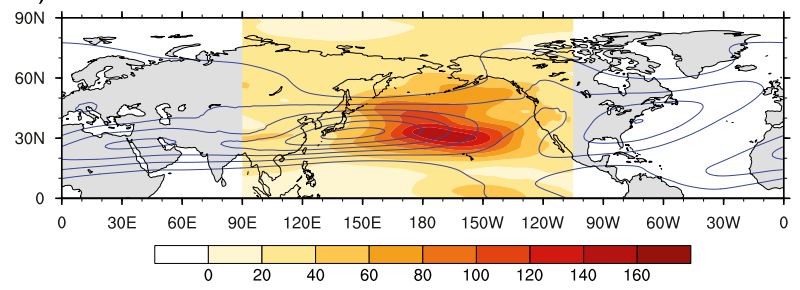

FIG. 1. (a)-(c) The color shadings show the first three EOF patterns of DJF 300-hPa monthly zonal wind $\left(\mathrm{m} \mathrm{s}^{-1}\right)$ from 1979 to 2016 over the Pacific region $\left(0^{\circ}-90^{\circ} \mathrm{N}, 90^{\circ} \mathrm{E}-135^{\circ} \mathrm{W}\right)$. The green contours show the climatology of $300-\mathrm{hPa}$ zonal wind in DJF from 1979 to 2016. Contour interval is $10 \mathrm{~m} \mathrm{~s}^{-1}$. (d) The shadings show the total variance of DJF 300-hPa monthly zonal wind $\left(\mathrm{m}^{2} \mathrm{~s}^{-2}\right)$ from 1979 to 2016 over the same region. The blue contours show the climatology of 300-hPa zonal wind in DJF from 1979 to 2016.

advection term in the following sections. The RWS term $S^{\prime}$ is related to the divergent wind:

$$
S^{\prime}=-\bar{\zeta} \nabla \cdot \mathbf{v}_{\chi}^{\prime}-\mathbf{v}_{\chi}^{\prime} \cdot \nabla \bar{\zeta}-\zeta^{\prime} \nabla \cdot \overline{\mathbf{v}}_{\chi}-\overline{\mathbf{v}}_{\chi} \cdot \nabla \zeta^{\prime},
$$

where $\mathbf{v}_{\chi}$ is divergent wind vector. The first two terms on the rhs of Eq. (3) represent the vorticity generation due to divergence of anomalous divergent wind and advection of background absolute vorticity by anomalous divergent wind. The third and fourth terms on the rhs of Eq. (3) are vorticity generation by convergence of the background flow and advection of the anomalous vorticity by background divergent wind, respectively.

The background flow impacts on Rossby waves propagation has been diagnosed by Karoly (1983) and Hoskins and Ambrizzi (1993) utilizing the stationary wavenumber $K_{s}$ on Mercator coordinates:

$$
K_{s}=\left(\frac{a \beta_{M}}{\bar{u}_{M}}\right)^{1 / 2}
$$

where $a$ is the radius of Earth, and the Mercator zonal wind $\bar{u}_{M}$ is the $300-\mathrm{hPa}$ background zonal wind divided by the cosine of the latitude. Also, $\beta_{M}$ is the meridional gradient of absolute vorticity on a sphere, which is defined as

$$
\beta_{M}=\frac{2 \Omega \cos ^{2} \theta}{a}-\frac{\partial}{\partial y}\left[\frac{1}{\cos ^{2} \theta} \frac{\partial}{\partial y}\left(\bar{u}_{M} \cos ^{2} \theta\right)\right],
$$

where $\Omega$ is Earth's rotational rate and $\theta$ is latitude. Rossby waves with zonal wavenumber $k$ are expected to be reflected at or decay beyond the turning latitude, where $K_{s}=k$. As the Rossby waves are refracted toward regions where $K_{s}>k$, the Rossby waves cannot propagate into regions where $K_{s}<k$. In other words, the Rossby waves have to propagate within the region defined by $K_{s}=k$ (also see Fig. 7). Thus, as discussed in Hoskins and Ambrizzi (1993), the regions where $K_{s}$ is maximized, for example the westerly jets, act as waveguides. In addition, Rossby waves cannot propagate into regions where $K_{s}^{2}<0$, that is, regions in which the background wind $\bar{u}_{M}$ is easterly, or where the absolute vorticity gradient $\beta_{M}$ is negative. As the gradient of planetary vorticity [first term on the rhs of Eq. (5)] is always positive, $\beta_{M}$ can only be negative over regions where the second derivative of the zonal wind in the meridional direction is large [second term of the rhs of Eq. (5)].

Following Simmons et al. (1983), an approximation for the barotropic energy exchange from background state to eddy component can be represented as

$$
\frac{\partial \mathrm{EKE}}{\partial t}=-\left(u^{\prime 2}-v^{2}\right) \frac{\partial \bar{u}}{\partial x}-u^{\prime} v^{\prime} \frac{\partial \bar{u}}{\partial y},
$$

where EKE represents eddy kinetic energy and $u$ and $v$ are zonal and meridional wind, respectively. Similar to previous equations, the prime represents the perturbation and the overbar represents the background mean flow. This equation may also be written as

$$
\frac{\partial \mathrm{EKE}}{\partial t}=\mathbf{E} \cdot \nabla \bar{u},
$$

with

$$
\mathbf{E}=-\left(u^{\prime 2}-v^{\prime 2}, u^{\prime} v^{\prime}\right)
$$

The vector $\mathbf{E}$ can be considered as an effective flux of westward momentum, or as the horizontal components of an extended Eliassen-Palm flux (Hoskins et al. 1983). 
The MJO-induced Rossby waves can extract energy from the background mean flow when the direction of the $\mathbf{E}$ vector is pointing upgradient toward extratropical background flow.

After the MJO heating is imposed into the model, the total flow around the globe deviates from the background mean flow. In all the following analyses, we consider the perturbations, which are relatively small, to be the Rossby waves excited by the heating. Thus, the background flow in the midlatitudes is considered not to be changed by the Rossby waves. Note that some previous studies (e.g., Moore et al. 2010) have shown that the subtropical jet can be modulated by the MJO as it propagates eastward. This can modulate the evolution of the MJO induced Rossby waves. The modulation of the jet by the MJO is not considered in our definition of the background mean flow, as we assume the background flow to be not changing. This is a limitation of our analysis method.

\section{Realistic and stationary MJO heating}

The MJO extratropical response in the reanalysis is evaluated at $300 \mathrm{hPa}$. Following Zheng and Chang (2019), lag composites of MJO with respect to the eight MJO phases and lag days $0-25$ are made at each grid point. An example of the lag composite is shown in Fig. 2b [the same as Fig. 2b in Zheng and Chang (2019)]. The lag composite is for the region over North Pacific (the blue box in Fig. 2a). For each grid point, from lag day 0 to day 25, there are 208 values for the eight phases in total. We calculate the root-mean-square (RMS) of these 208 values for each grid point and plot that on the map [Fig. 2a; the same as Fig. 2a in Zheng and Chang (2019)]. Similar figures are plotted to evaluate the REAL_MJO experiment with different basic states in the model (Fig. 2). As discussed in Zheng and Chang (2019), the model can reasonably capture the timing and location of the MJO extratropical response over the Pacific and North America, while the amplitude of the response over North Atlantic is underestimated with respect to the reanalysis (also see Figs. 2c and 2a). Note that, as discussed in Zheng and Chang (2019), the composites for MJO extratropical response in the reanalysis (after 1979) are not entirely robust and adding or removing a few years data can significantly modify the composites. If we divide the reanalysis data into different categories (e.g., positive and negative EOF1), the composites are very noisy (not shown) and the differences between different categories are likely dominated by noise instead of just being due to the differences corresponding to the different basic states. So, here we only compare our control model results (climatological basic state) with the reanalysis (all of the winter data from 1979 to 2016).

Figure 2 shows that the MJO extratropical response exhibits large differences when the background state is different. The wave train in positive EOF1 is more zonally oriented compared to positive EOF1 over the Pacific. In comparison with the climatological basic state, both positive and negative EOF1 give rise to stronger response over the Pacific, with the maximum response moving from central North Pacific for negative EOF1 to eastern North Pacific for positive EOF1. Similarly, the maximum response over the Pacific also shifts eastward from positive EOF2 to negative EOF2. In comparing positive and negative EOF2, it is seen that positive EOF2 has stronger response over North America while negative EOF2 has stronger response over the North Pacific. For EOF3, the response in negative EOF3 is strong over both the Pacific and North America. Although Fig. 2 just shows the average of the extratropical response for lag day 0-25 during eight phases, these differences in magnitude and location of the extratropical response mentioned above also exist in the composites of individual lag days (not shown).

As shown in Zheng and Chang (2019), in terms of stationary MJO heating of a single RMM phase, phase-2 heating generates the strongest extratropical response. The 300-hPa geopotential height anomalies from day 0 to day 36 in climatological basic state for PHASE2_15days experiments are shown in Fig. 3 as an example of the evolution of the extratropical response. We can clearly see the development and strengthening of the wave train up to nearly day 20 , and continued propagation across North America long after the heating is switched off on day 15. The MJO extratropical response for the PHASE2_15days experiments with different background states are summarized in Fig. 4. To better compare with the realistic MJO heating, the RMS of extratropical response from days 10 to 35 (the map for each day is similar to panels in Fig. 3) at each grid point is plotted. There are a lot of similarities between Figs. 2 and 4. The locations of the maximum response over the Pacific, near Alaska and western Canada, and over eastern North America for the different basic states, are almost identical for propagating MJO heating (Fig. 2) and stationary phase-2 heating (Fig. 4). For example, the response over the Pacific shifts eastward from positive EOF2 to negative EOF2. The intensity of the extratropical response, except for that for EOF1 over North America, is also consistent between propagating MJO heating (Fig. 2) and stationary heating (Fig. 4). For example, comparing positive and negative EOF2, positive EOF2 has stronger response over North America, while negative EOF2 has stronger response over the 
a) Reanalysis

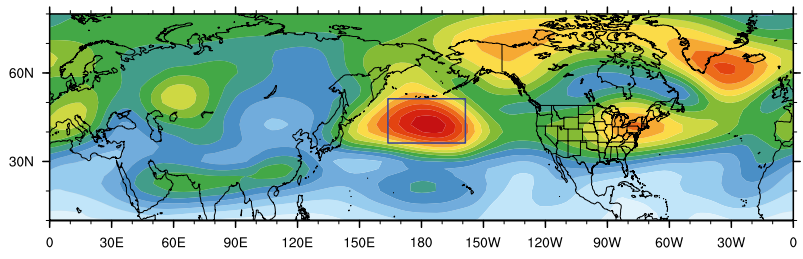

c) Climatology b) Lag composite for the blue box

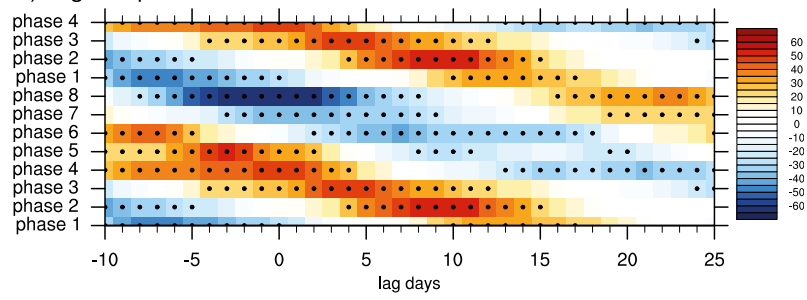

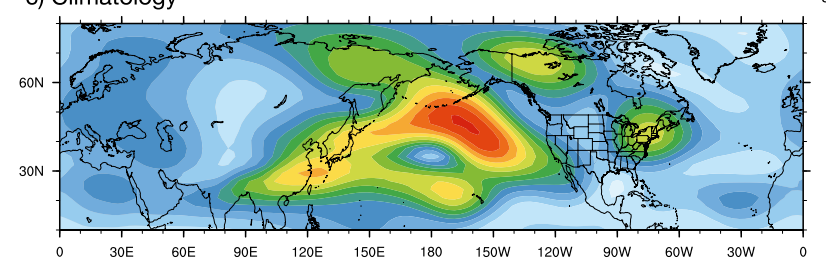

d) EOF1 +1 std

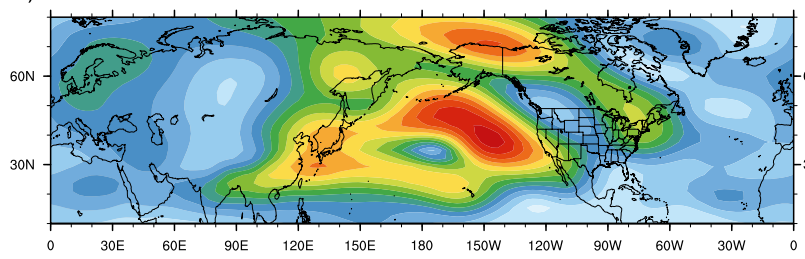

e) EOF1 -1std

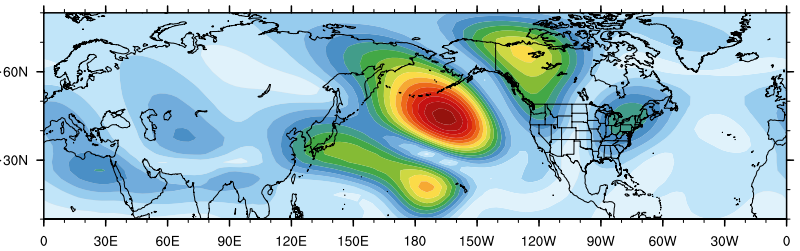

f) EOF2 +1std

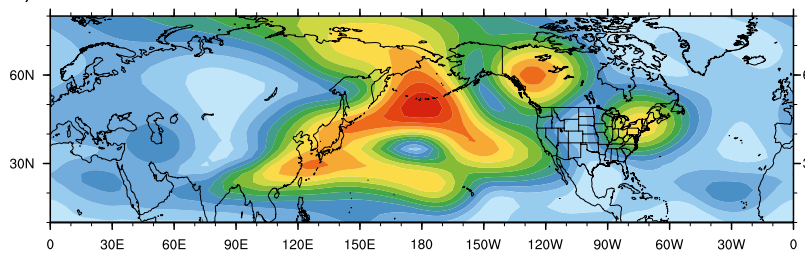

g) EOF2 -1std

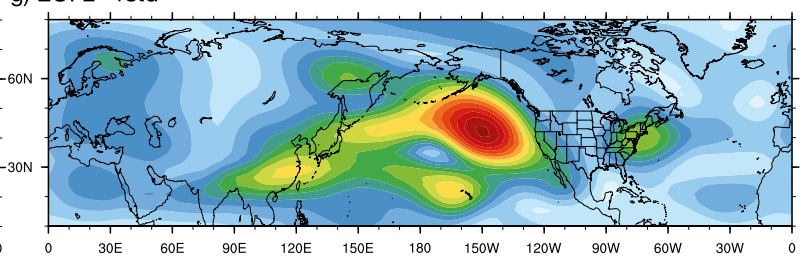

h) EOF3 +1std

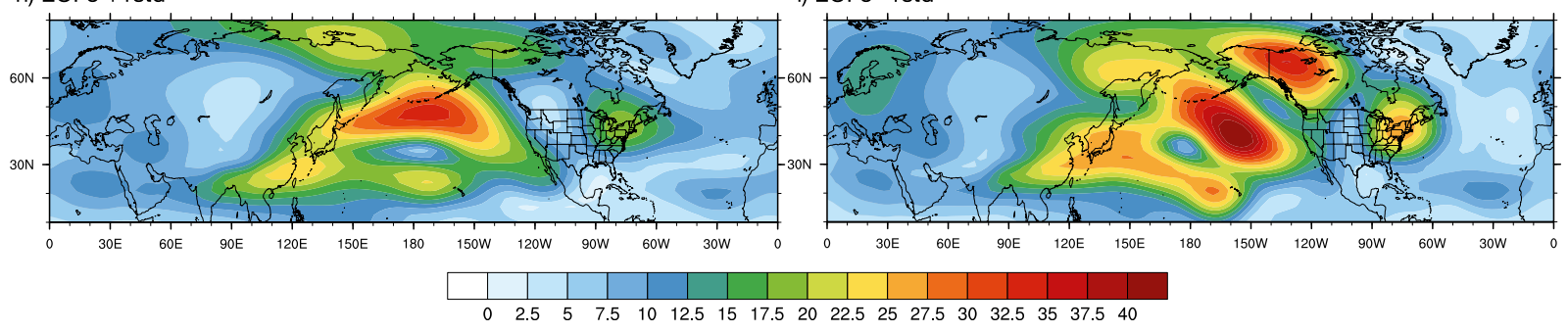

FIG. 2. (a) RMS of the 300-hPa geopotential height anomaly (m) of eight RMM phases and lag days from 0 to 25 in the reanalysis. This panel is the same as Fig. 2a in Zheng and Chang (2019). (b) An example of the lag composite of 300-hPa geopotential height anomaly (m) with respect to eight different phases and lag day from -10 to 25 . The composite is for the region over the blue box in (a). This panel is the same as Fig. 2 b in Zheng and Chang (2019). The dotted days are statistically significant from the results of a Monte Carlo test. The detailed method of the test can be found in Zheng et al. (2018). (c) As in (a), but the geopotential height anomaly is the response to the REAL_MJO heating (see text for details) in the model when the model basic state is winter climatological background flow. (d)-(i) As in (c), but the model basic states are respectively +1 standard deviation of the EOF1-associated pattern, -1 standard deviation of the EOF1-associated pattern, +1 standard deviation of the EOF2-associated pattern, -1 standard deviation of the EOF2-associated pattern, +1 standard deviation of the EOF3-associated pattern, and -1 standard deviation of the EOF3-associated pattern superposed onto climatological background flow.

North Pacific. Thus, the stationary RMM phase heating (PHASE2_15days) experiments can qualitatively represent the location and intensity of the experiments with realistic MJO heating. As the role of MJO propagation on modulating the MJO extratropical response has already been discussed by Zheng and Chang (2019), and stationary phase 2 heating is less complex than propagating heating, which makes it more straightforward to be analyzed, only the results from the stationary phase 2 heating (PHASE2_15days experiments) will be discussed in the following sections. Note that the similarities between Figs. 2 and 4 indicate that the conclusions reached 
a) Climatology basic state day 0

f) Climatology basic state day 20
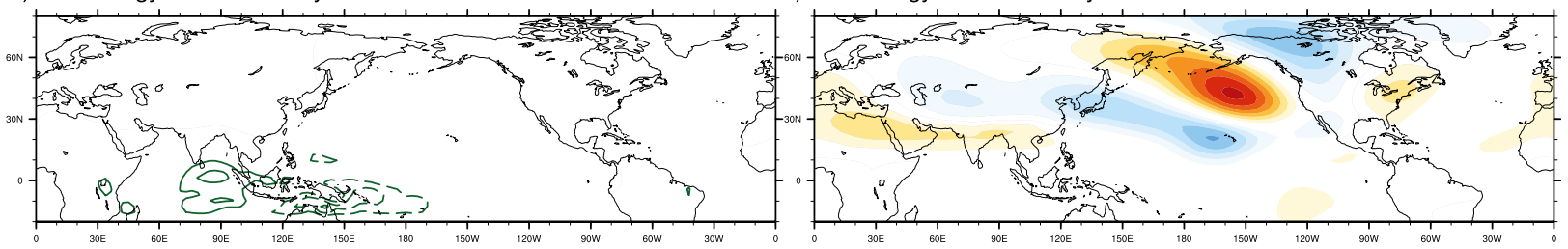

b) Climatology basic state day 4

g) Climatology basic state day 24

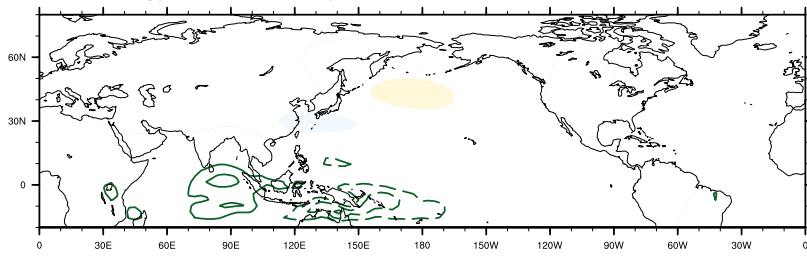

c) Climatology basic state day 8
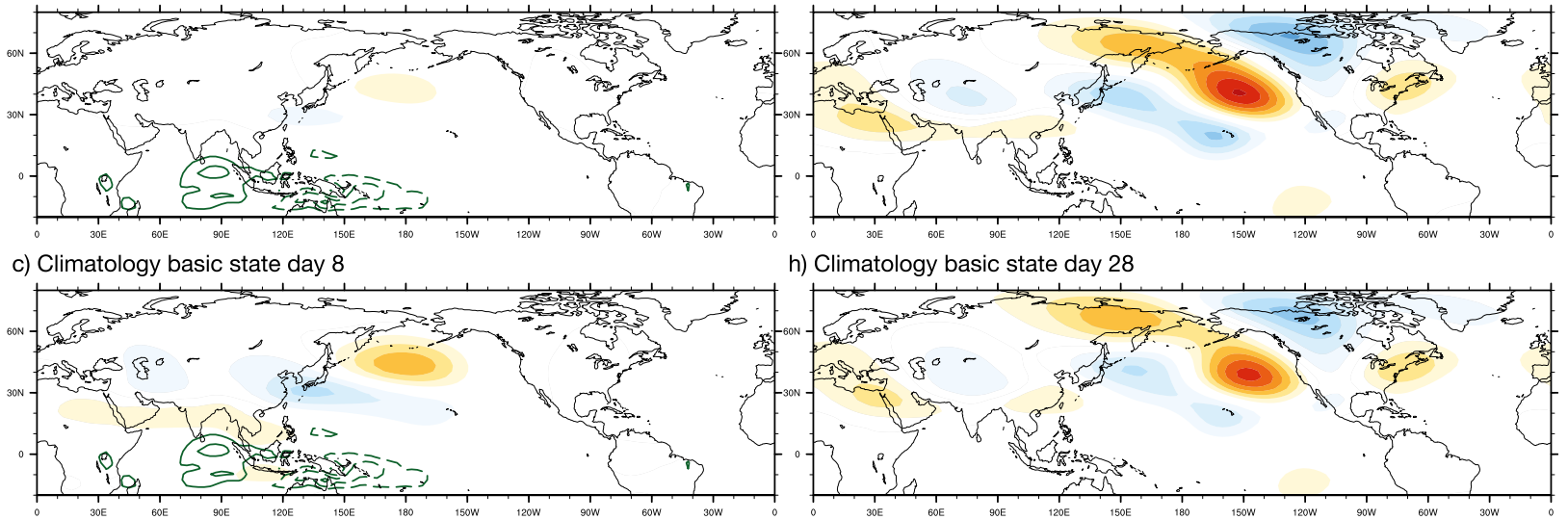

h) Climatology basic state day 28

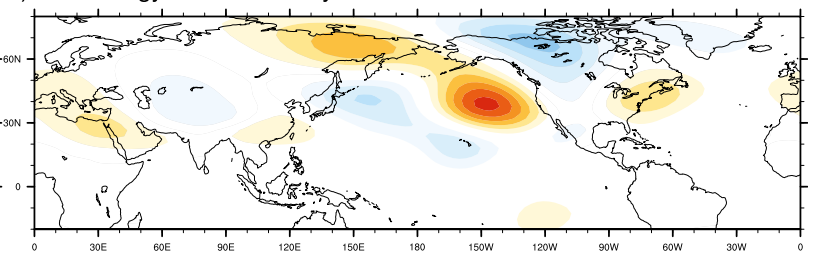

d) Climatology basic state day 12

i) Climatology basic state day 32

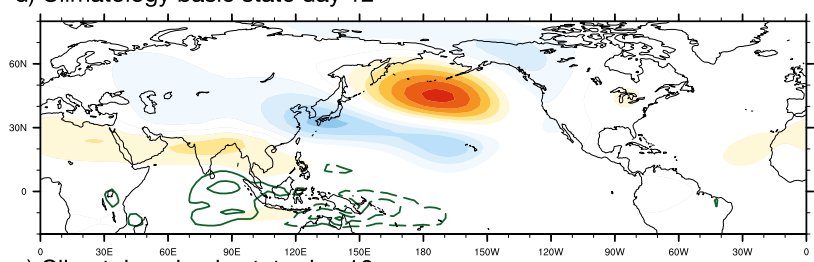

e) Climatology basic state day 16

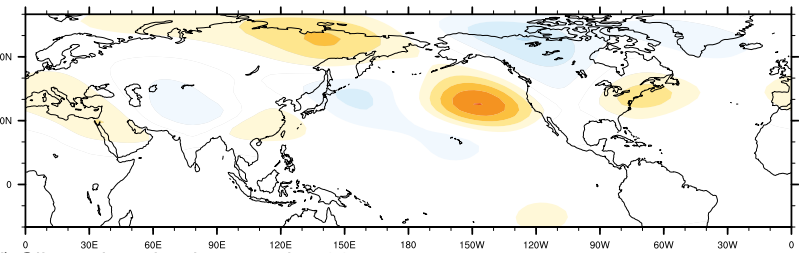

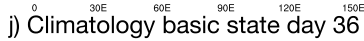

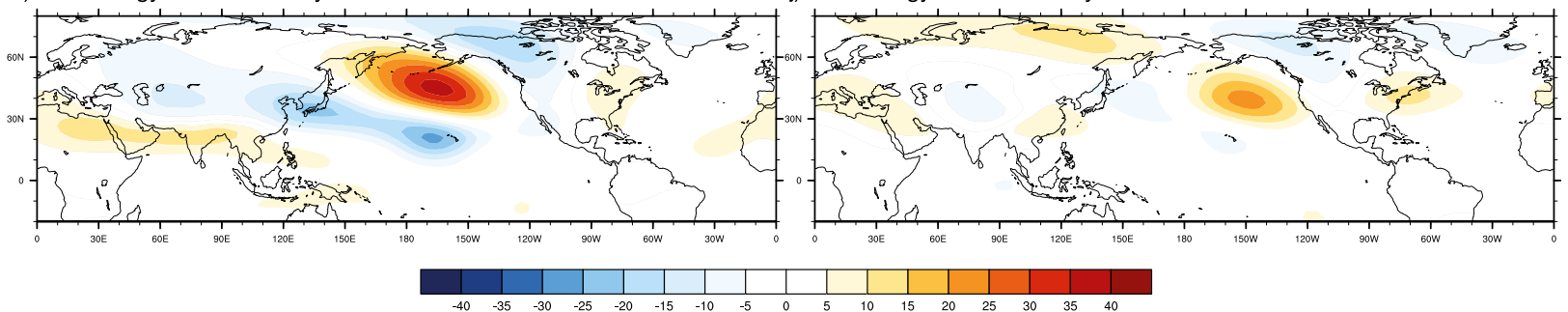

FIG. 3. The evolution of 300-hPa geopotential height anomaly $(\mathrm{m})$ from day 0 to day 36 PHASE2_15days experiments in climatological basic state. In (a)-(d), the mean temperature tendency (the MJO heating as an external forcing for the model) from the surface to $100 \mathrm{hPa}$ is plotted in green contours (solid lines for positive contours, and dashed lines for negative contours).

from stationary heating experiments can be applied to qualitatively interpret the propagating MJO heating experiments.

\section{Initial vorticity anomalies induced by the MJO}

The RWS of the different basic states at day 2 in the PHASE2_15days experiments is shown in Fig. 5. Here, the goal is to analyze how the MJO heating induces the initial vorticity tendency, but not to focus on the propagation of the Rossby wave, as that will be discussed in section 5a. Thus we analyze the RWS and vorticity tendency at day 2 , since during later days it becomes hard to separate vorticity tendency due to MJO heating and due to the evolution or propagation of the Rossby waves on its own. This analysis is similar to the method used by Seo and Lee (2017), in which they discussed the RWS induced by the MJO heating 3 days after the MJO heating is turned on. We focus on the region near the jet over the Pacific, as it is related to the MJO extratropical response over the Pacific. Positive EOF1, as well as negative EOF2 and EOF3, gives rise to stronger RWS, compared with the climatological basic state, or the basic states with opposite EOF pattern respectively. The RWS generated by the MJO has been analyzed in detail by Seo and Lee (2017). They found that the 


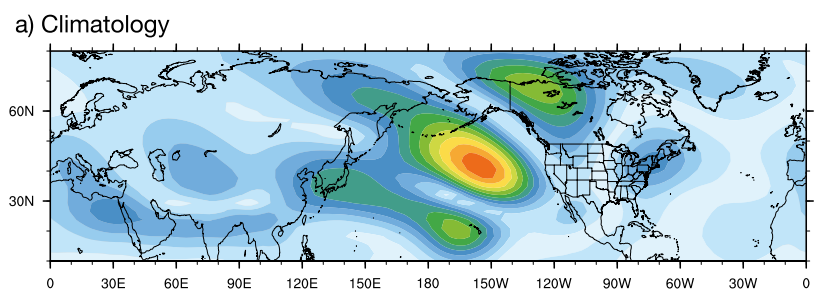

b) EOF $1+1$ std

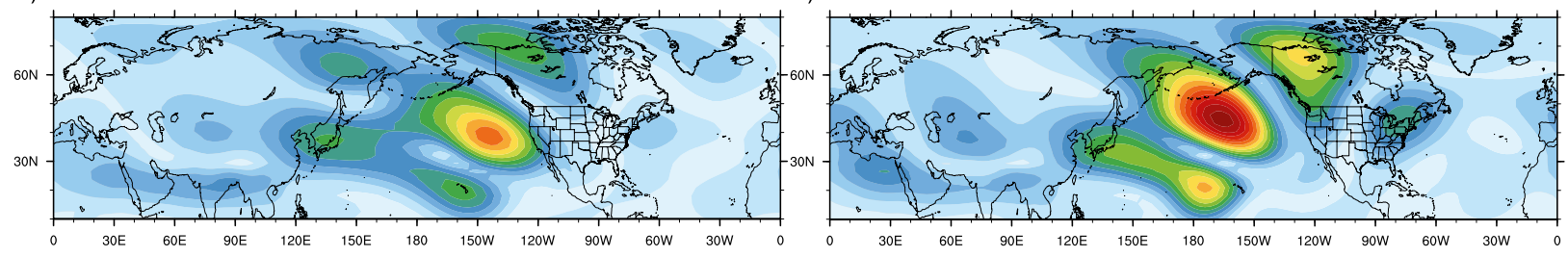

d) EOF2 +1 std

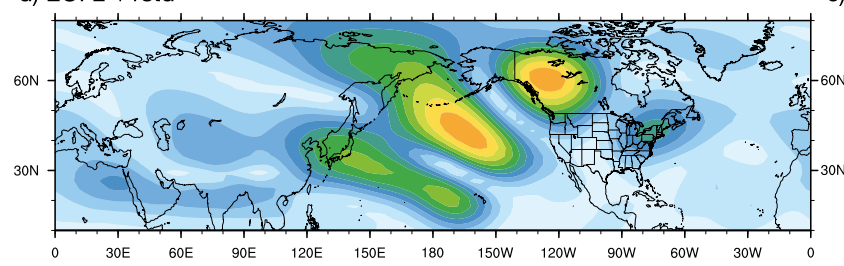

e) EOF2 -1std

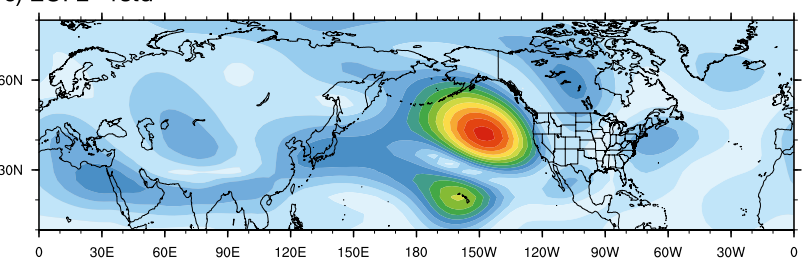

f) $\mathrm{EOF} 3+1$ std

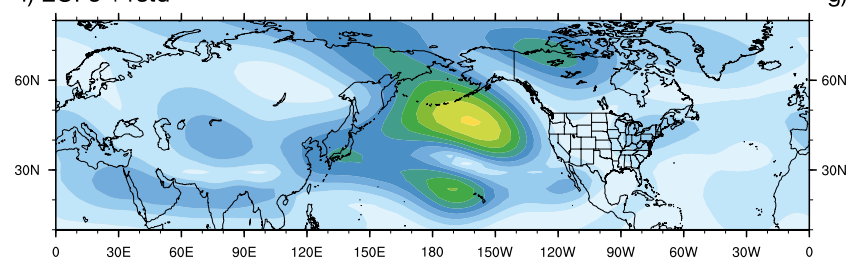

g) EOF3 -1std
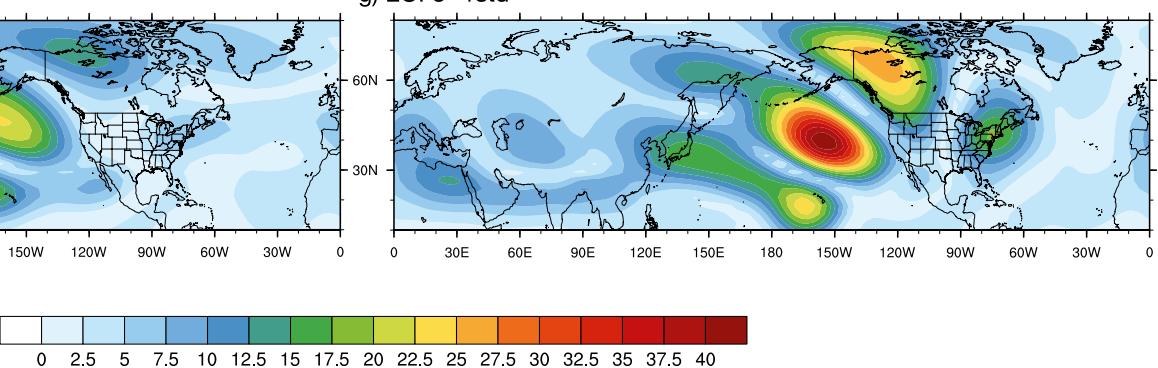

FIG. 4. As in Figs. 2c-i, but the heating imposed into the model is stationary phase-2 heating for 15 days (PHASE2_15days), and RMS is calculated from day 10 to 35 of the experiment.

second term in Eq. (3), which is the advection of the background vorticity by the anomalous divergent flow, gives rise to the major contribution to the RWS [consistent with Sardeshmukh and Hoskins (1988); Mori and Watanabe 2008]. The four terms on the rhs of Eq. (3) are shown in Figs. S1-S4 in the online supplemental material. Consistent with Seo and Lee (2017), the second term (Fig. S2) provides the largest contribution to the RWS for the different background states. As the MJO-related heating is the same for the different basic states, the anomalous divergent wind is very similar for the different experiments. Hence the differences in the RWS (Fig. 5), which are primarily due to the differences in the second term (Fig. S2), are due to the differences in the background absolute vorticity gradient (Fig. S5 in the online supplemental material). This is true for the cases in which the RWS is stronger (positive EOF1; negative EOF2 and EOF3), the absolute background absolute vorticity gradient is also stronger. Generally, the absolute vorticity gradient is larger if the background jet is stronger and sharper. Consistently, the cases when RWS is stronger coincide with the cases when the jet is stronger (Fig. 5).

Will larger RWS lead to stronger extratropical response? The vorticity tendency in Eq. (2) is shown in Fig. 6. For EOF1 and EOF3, the cases with larger vorticity tendency do correspond to the cases with larger RWS. However, for EOF2, positive EOF2 has smaller RWS than negative EOF2, but ends up with larger vorticity tendency (the peak positive value of vorticity tendency is $1.8 \times 10^{-11}$ for positive EOF2 and is $1.2 \times 10^{-11}$ for negative EOF2 over the North Pacific). The reason is due to the rotational advection terms in Eq. (2). The stronger jet does not only give rise to stronger RWS, but also leads to stronger vorticity advection by the background rotational wind (Fig. S6 in 


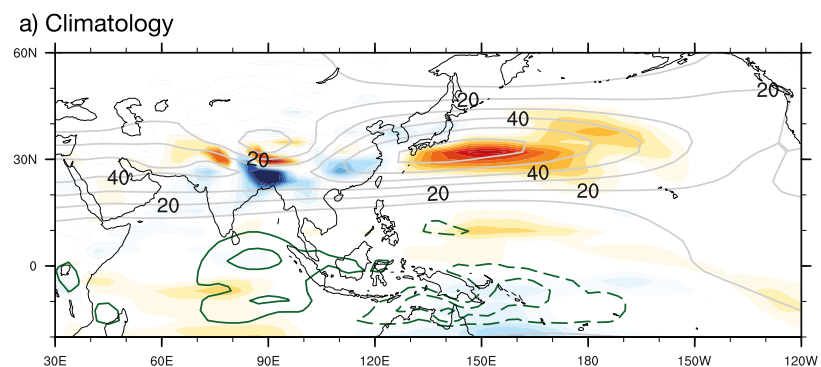

b) EOF $1+1$ std

c) EOF1 - 1 std

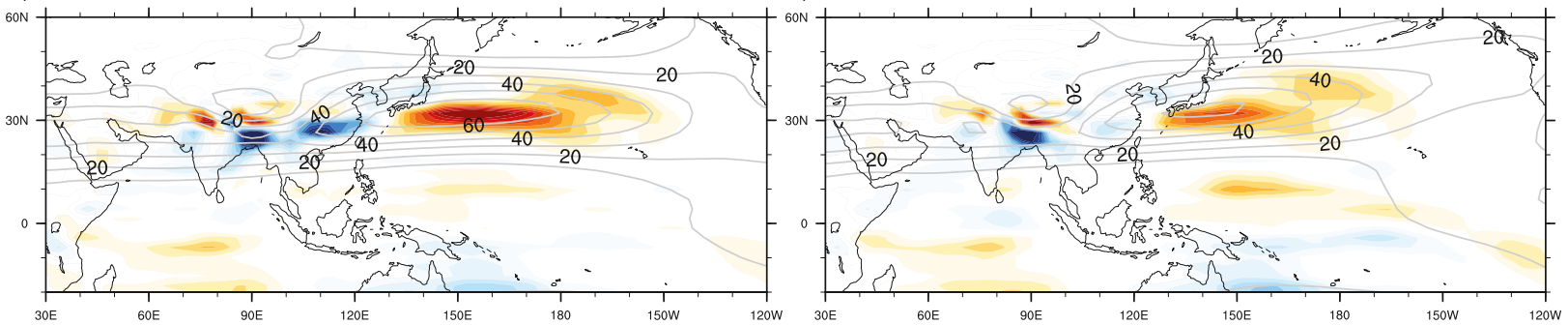

d) EOF2 +1std

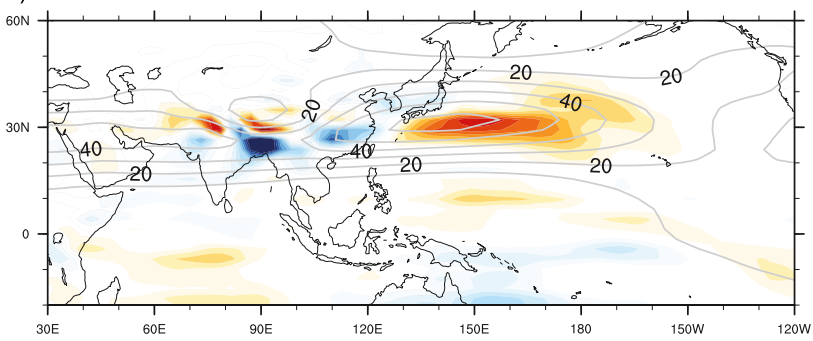

e) EOF2 -1std

f) EOF $3+1$ std
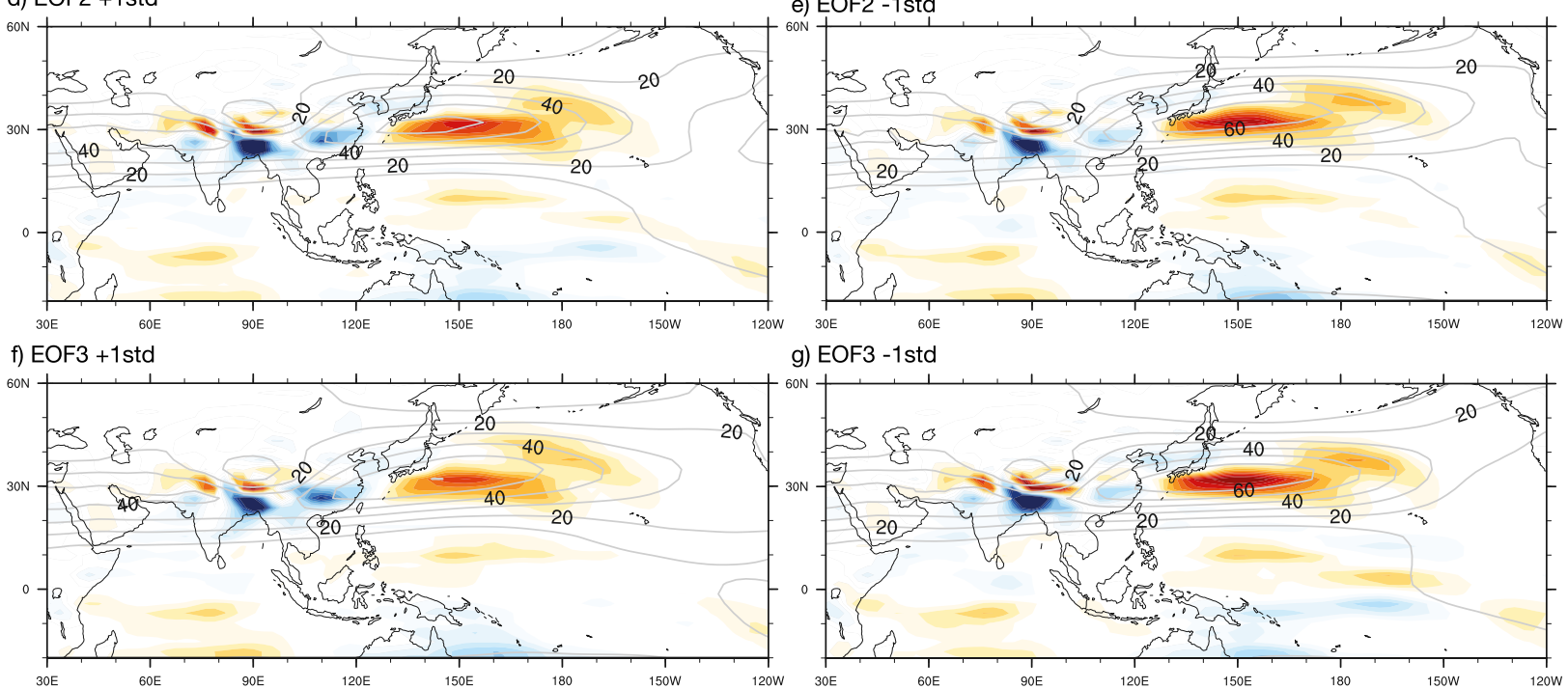

g) EOF3 -1std
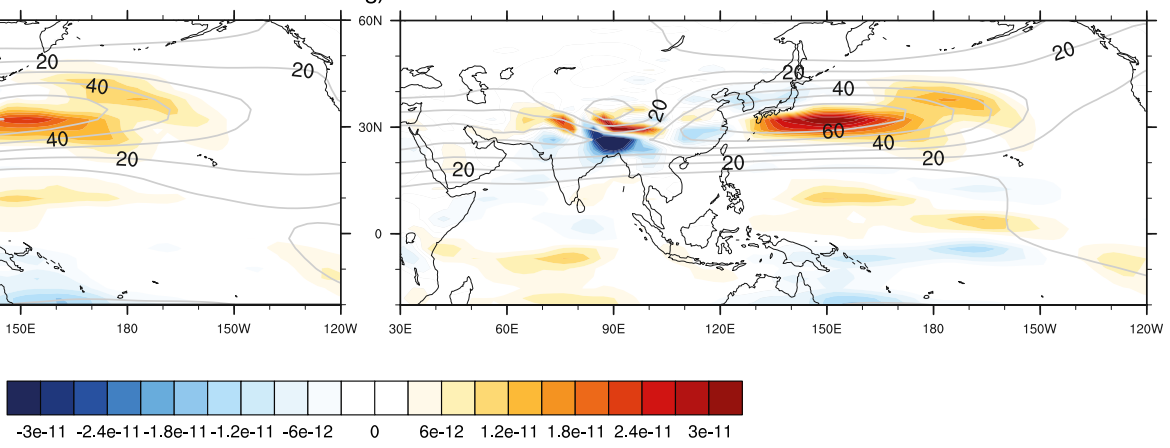

FIG. 5. The shadings show the Rossby wave source $\left(\mathrm{RWS} ; \mathrm{s}^{-2}\right.$ ) at $300 \mathrm{hPa}$ at day 2 of PHASE2_15days experiments. The gray contours show the basic state $300-\mathrm{hPa}$ zonal wind. Solid contours are positive, dashed contours are negative, and the zero contour is omitted. Contour interval is $10 \mathrm{~m} \mathrm{~s}^{-1}$. The mean temperature tendency (the MJO heating as an external forcing for the model) from the surface to $100 \mathrm{hPa}$ is plotted in green contours (solid lines for positive contours, and dashed lines for negative contours) in (a). Solid contours are positive, dashed contours are negative, and the zero contour is omitted. Contour interval is $0.25 \mathrm{~K} \mathrm{day}^{-1}$. Similar to Figs. 2c-i, each panel is for a different basic state. The "e" in the key indicates that the preceding number should be multiplied by 10 raised to the following number.

the online supplemental material). The enhanced rotational advection for negative EOF2 relative to positive EOF2 compensates for the enhanced RWS, leading to weaker vorticity tendency for negative EOF2. However, for positive EOF1 and negative EOF3, although the rotational advection is also enhanced, it is not enough to compensate for the enhanced RWS. Therefore, the vorticity tendency in these cases is still stronger relative to negative EOF1 and positive EOF3.

While the RWS gives rise to the positive vorticity tendency at the southern flank of the jet, the dispersion (or propagation) of the Rossby waves leads to the negative vorticity tendency at the northern flank of the jet. As shown in Fig. S7 in the online supplemental material 


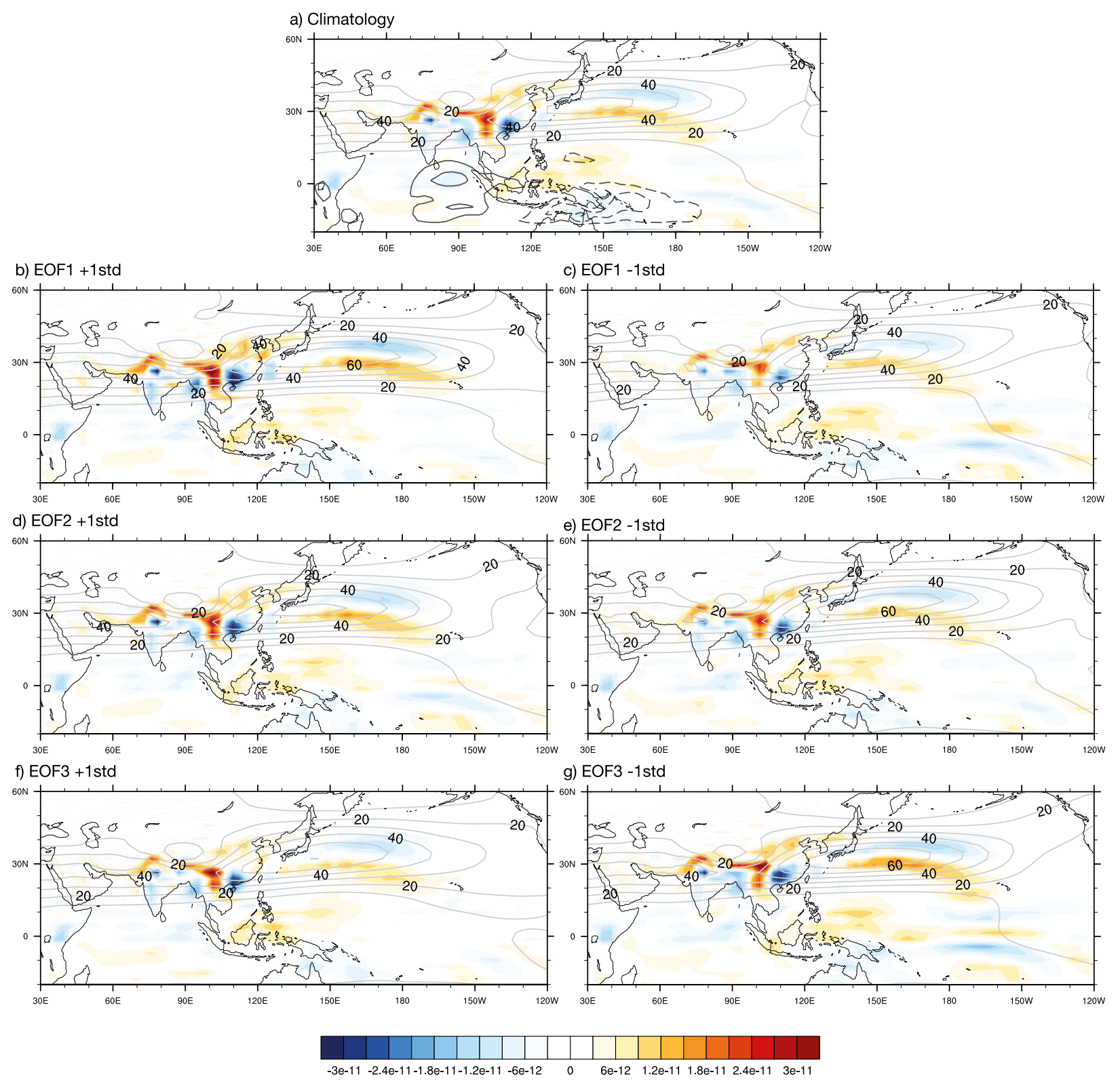

FIG. 6. As in Fig. 5, but the shadings shows the vorticity tendency.

(only the climatological basic state is shown), the third term on the rhs of Eq. (2), which is the advection of the background vorticity by the anomalous rotational wind, is responsible for the negative vorticity anomaly. The second term on the rhs of Eq. (2), which is the advection of the vorticity anomaly by the background rotational wind (Fig. S8 in the online supplemental material), moves the vorticity anomalies eastward. This dispersion of the Rossby wave due to the background vorticity advection by the anomalous wind is similar to downstream development, which has been discussed in previous studies (e.g., Chang 1993; Blackmon et al. 1984).
These negative and positive vorticity anomalies give rise to the positive and negative geopotential height anomalies respectively.

The geopotential height anomalies at days 2, 4, and 6 for different basic states are respectively shown in Figs. S9-S11 in the online supplemental material. The amplitude of the geopotential height anomaly is consistent with the amplitude of the vorticity tendency. Overall, the vorticity tendency largely explains the major characteristics of the positive height anomaly over the Pacific for phase 2 stationary heating during the early stage of the experiment. The extratropical 


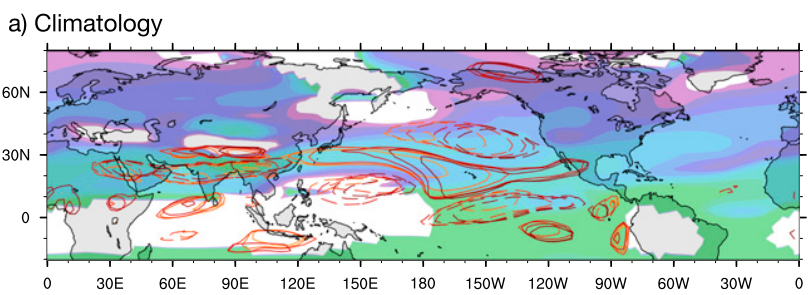

b) EOF1 $+1 \mathrm{std}$

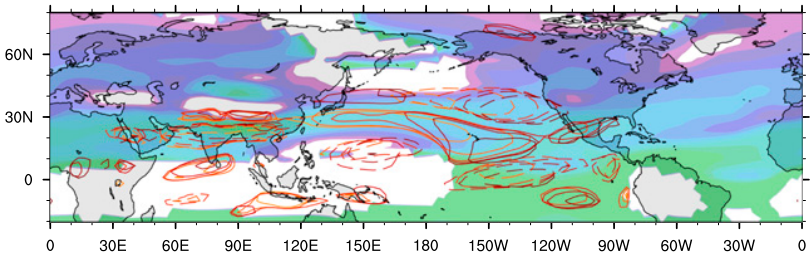

d) EOF2 +1std

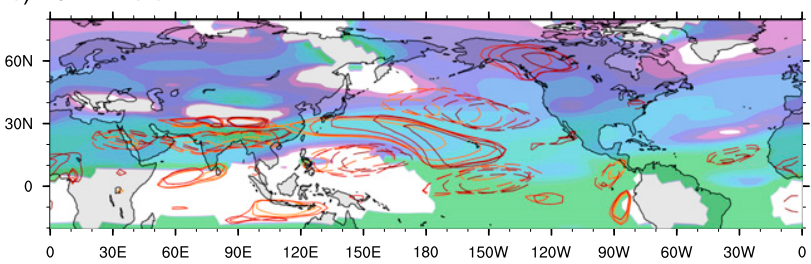

f) EOF3 +1std

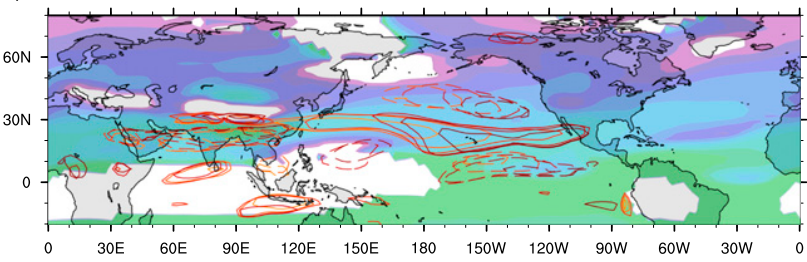

g) EOF3 -1sto

c) EOF1 -1std

e) EOF2 -1std
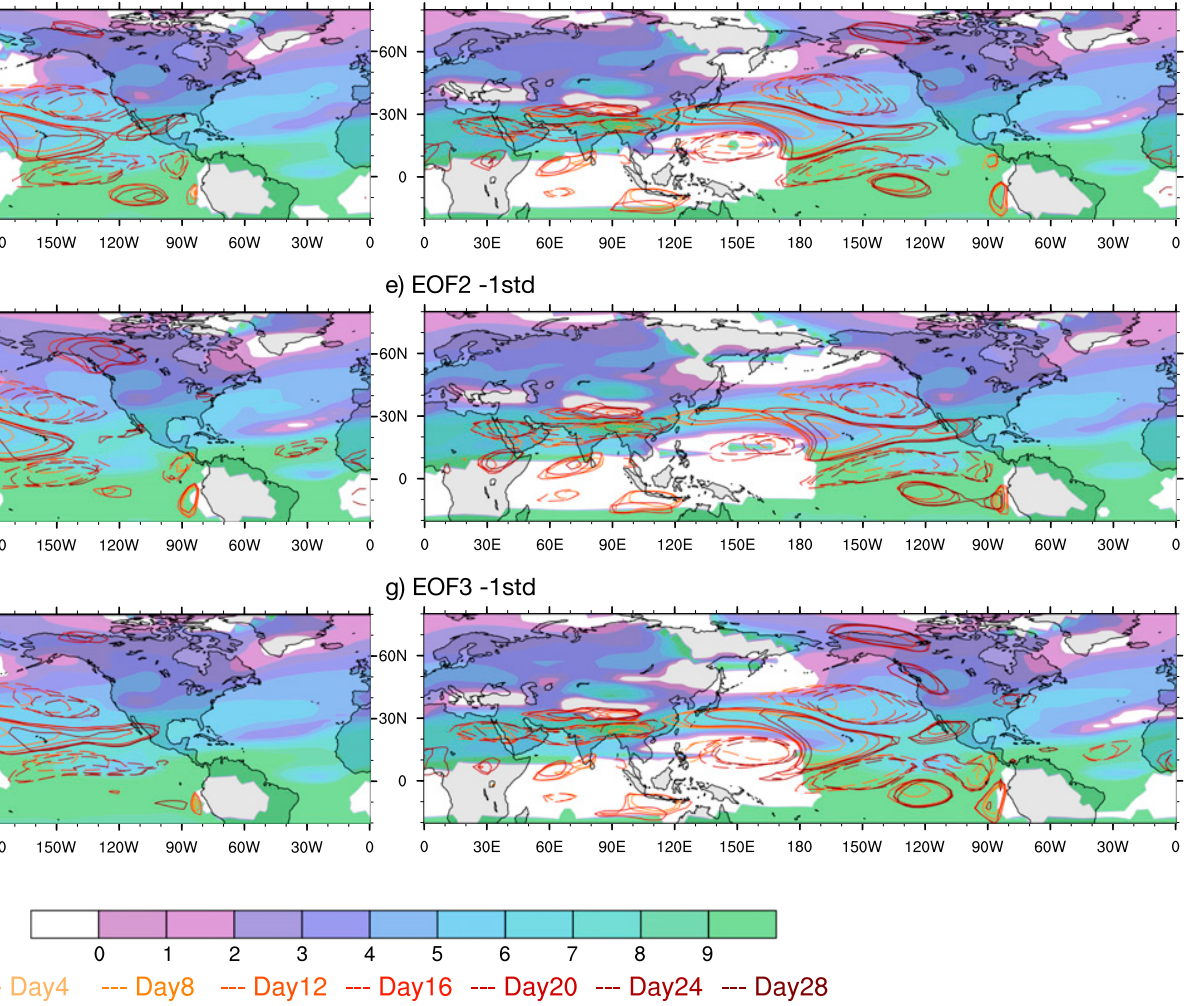

FIG. 7. The color shadings show the stationary wavenumber $K_{s}$ at $300 \mathrm{hPa}$. The regions in white color are where there is no realnumber solution for $K_{s}$. The contours are the $\pm 3 \times 10^{-6} \mathrm{~s}^{-1}$ vorticity anomaly contour line for days 4, 8, 12, 16, 20,24, and 28 in the PHASE2_15days experiment at $300 \mathrm{hPa}$. Solid contours are positive; dashed contours are negative. Similar to Figs. 2c-i, each panel is for a different basic state.

response is growing mainly over the western North Pacific and the central North Pacific and is in relatively small amplitude during this stage compared with later stages (see section 5). The MJO heating will further amplify these anomalies. The evolution and propagation of the Rossby waves discussed in the next section will bring these anomalies to eastern North Pacific, North America, and regions farther downstream.

\section{Rossby wave propagation and evolution}

\section{a. Rossby waveguide}

From Figs. 2 and 4, geopotential height anomalies can hardly reach into North America for the negative EOF2 basic state but can reach into North America for the other basic states. The main reason is that the distribution of stationary wavenumber $K_{s}$, or the waveguide, prohibits the wave to propagate northward for negative EOF2. The stationary wavenumber $K_{s}$ for the different background flows is shown in Fig. 7. Over the white regions, either the zonal wind $\bar{u}_{M}$ is easterly, where the stationary Rossby wave cannot propagate following Rossby wave theory, or $\beta_{M}$ is less than zero, where the meridional gradient of absolute vorticity is reversed, and the stationary Rossby waves must turn before reaching these latitudes (e.g., Hoskins and Ambrizzi 1993). Over these regions, $\beta_{M} / \bar{u}_{M}$ is negative. Following Eq. (4), the solution for $K_{s}$ is an imaginary number but not a real number. These regions are in white color, which indicates there is no real number solution for $K_{s}$. Thus, stationary 
Rossby waves are prohibited to propagate into the white regions. The anomalous vorticity from day 4 to 28 in the experiments, depicted by the $\pm 3 \times 10^{-6} \mathrm{~s}^{-1}$ contour lines in Fig. 7, cannot reach the white regions in the midlatitudes. The vorticity anomalies can appear in the white regions in the tropics because the vorticity anomalies in the tropics are directly generated by the MJO heating and are not due to Rossby wave propagation. Thus, in our experiments, the stationary wavenumber $K_{s}$ well depicts where the Rossby waves can propagate. For negative EOFs 1, 2, and 3, as well as positive EOF3, the white shadings cover the regions from the Sea of Okhotsk to the Aleutian Islands. Over the eastern part of the Aleutian Islands, Rossby waves are allowed to propagate. Thus, the Rossby waves propagate eastward and northward, reaching Alaska and eventually the eastern part of North America. For negative EOF2, as the jet extends eastward and shifts northward, the regions where the absolute vorticity gradient reverses sign also extend eastward. The white shading extends farther east, reaching the west coast of North America for negative EOF2. Then $K_{s}$ prohibits the stationary Rossby wave propagation into regions near Alaska. Therefore, the vorticity anomalies are trapped in the Pacific. The vorticity anomalies are also trapped in the Pacific when the basic state has a large amplitude for positive EOF1 (see Fig. S12b in the online supplemental material for a basic state with positive 2 standard deviations of EOF1). Also note that the method used here is similar to that in Henderson et al. (2017) in which they analyze the different basic states in CMIP5 models. Our findings are very consistent with their results that the regions where stationary Rossby waves cannot propagate (no real number solution for $K_{s}$ ) determine the pathway of the MJO-induced Rossby waves in the extratropics.

When the jet extends eastward (positive EOF1 and negative EOF2), the extratropical response over North Pacific shifts eastward. This is also true in the model simulations in Henderson et al. (2017) when the background jet in CMIP5 models has an eastward extension. When there is a southward shift of the jet (positive EOF2), the extratropical response over North America is stronger when compared with climatological basic state or when there is a northward shift (negative EOF2). Model simulations in Henderson et al. (2017) where there is a southward shift of the jet also show large amplitude of extratropical impact over North America. Similar to the discussion earlier in this section, when there is a southward shift of the jet, background vorticity gradient increases in the northern flank of the jet as the curvature of the zonal wind decreases over the northern flank [see Eq. (5)]. This will make $K_{s}$ larger over the northern flank of the jet, compared towhen there is a northward shift of the jet. Larger $K_{s}$ favors Rossby wave to propagate to the north over the northern flank of the jet and then into North America (opposite to when the Rossby waves are trapped in the Pacific), Thus, a southward shift of the jet results in stronger extratropical response over North America.

\section{b. Barotropic energy exchange}

The temporal evolution of the Rossby waves at $300 \mathrm{hPa}$ for the climatological jet and \pm 1 standard deviations of EOFs 1, 2, and 3 from day 4 to day 32 are shown in Figs. 8-10. The shadings show the EKE generation by barotropic energy exchange, while the vectors are $\mathbf{E}$ vectors. From Eq. (7), to give rise to strong energy exchange from the background flow to EKE, the $\mathbf{E}$ vectors need to be strong at regions where the background has large gradient, and point toward upgradient of background zonal flow.

In Fig. 8, for positive EOF1, the jet strengthens and extends eastward, giving rise to enhanced zonal wind gradient in the jet exit region and the southern flank of the jet. As the $\mathbf{E}$ vectors associated with the Rossby waves are over these large gradient regions, Rossby waves are amplified by the energy exchange. For negative EOF1, although the background flow is weaker compared to the climatological background flow, the regions where the $\mathbf{E}$ vectors are large are closer to the jet core region where the gradient of zonal wind is larger, as the positive geopotential height anomaly is shifted westward. Also, the northward tilt of the jet for negative EOF1 makes the large zonal wind gradient region closer to the positive geopotential height associated with the Rossby waves. Therefore, although the initial amplitude of the geopotential height anomalies is similar for negative EOF1 and the climatological jet, the larger energy exchange amplifies the Rossby wave for negative EOF1. The energy exchange, which is proportional to the amplitude of $\mathbf{E}$ vector, becomes even larger as the Rossby wave amplifies.

Note that Lin and Brunet (2018) found that when there is an intensification of the subtropical Pacific jet (consistent with positive EOF1 in this study as the jet enhances in its southern flank), the MJO-induced extratropical response shifts eastward from day 11 to day 15 . Our results during the same stage of the Rossby wave propagation are consistent with their results.

The Rossby waves for both positive and negative EOF1 are amplified by the energy exchange. The energy exchange maintains or even amplifies the waves after the heating is turned off at day 15 . However, because the jet is stronger for positive EOF1, the Rossby wave-associated anomalies are advected eastward more quickly relative to negative EOF1, in which the 
jet is weaker. As the positive geopotential height anomaly is advected away from the jet exit for positive EOF1, energy exchange stops and the anomalies decays. Meanwhile, the anomalies for negative EOF1 can stay close to regions where the zonal wind gradient is large such that energy exchange can last for a longer period, giving rise to more persistent extratropical response even well after the heating has been turned off.

In Fig. 9, the Rossby wave during the early stage is stronger for positive EOF2, which is consistent with the amplitude of vorticity tendency discussed in section 4 . The energy exchange is stronger for positive EOF2 from day 8 to 16 , as the $\mathbf{E}$ vectors are stronger. The wave train propagates into North America following the waveguide. As the anomalies move eastward and away from the high zonal wind gradient region after day 24, the Rossby wave decays. For negative EOF2, although initially the geopotential height anomalies are weaker, the large background zonal wind gradient due to the extended and strengthened background jet slowly amplifies the anomalies (similar to positive EOF1 in Fig. 8). The energy exchange is important for the amplification after day 15 as the MJO heating is turned off. This leads to strong geopotential height anomalies over the eastern North Pacific. However, the regions where there is no real solution for $K_{s}$ prohibit the Rossby wave from propagating northward, so the response near Alaska and eastern North America is relatively weak for negative EOF2.

Lin and Brunet (2018) found that when the jet shifts northward (consistent with negative EOF2 in this study), the MJO-induced extratropical response is weaker compared with when the jet shifts southward during day 11 to day 15. Our experiments for EOF2 during the same stage are consistent with that.

The evolution of the Rossby waves for \pm 1 standard deviations of EOF3 is shown in Fig. 10. The early response is stronger for negative EOF3. This is also consistent with the vorticity tendency discussed in section 4 . As the jet is also stronger with larger zonal wind gradient for negative EOF3, the anomalies for negative EOF3 are further amplified due to the large energy exchange, even though the MJO heating is turned off at day 15. As the waveguide also allows the Rossby wave to propagate into Alaska and eastern North America, negative EOF3 gives rise to the strongest response over North America in all the experiments examined in this study. For positive EOF3, as the initial anomalies are weaker (vorticity tendency is weaker; see section 4), the geopotential height anomalies are weaker before day 12. And with weaker zonal wind gradient to generate energy exchange from background flow to anomalous flow, the Rossby wave is weak and the impacts are limited to the Pacific.

\section{Discussion}

As shown in section 4, stronger background flow generally gives rise to stronger RWS. The main contribution is from advection of background vorticity by anomalous divergent flow generated by the heating source. However, when the rotational advection terms are also considered, the cases with stronger RWS do not necessarily end up with stronger vorticity tendency, as stronger jets also give rise to stronger advection. Thus, a stronger jet does not always lead to stronger vorticity tendency. The vorticity tendency then determines the location and strength of the initial Rossby wave-related anomalies (Fig. 6). For positive EOF1, negative EOF2, and negative EOF3, the jet is relatively strong, and the rotational advection is strong (online supplemental Fig. S6). Negative EOF3, which sharpens the jet (see the pattern in Fig. 1c), strongly enhances the vorticity gradient (online supplemental Fig. S5). For positive EOF1, the jet is enhanced in the southern flank. Then the vorticity gradient is stronger to the south of the climatological jet core, where it is closer to the MJO heating and the associated divergent flow is stronger. For negative EOF2, the jet is enhanced in the northern flank. So, the enhanced vorticity gradient is more to the north, especially when compared with positive EOF1 (Fig. S5). Because it is farther away from the MJO heating, the enhancement of the vorticity gradient for negative EOF2 is inefficient in generating RWS when compared with positive EOF1 and negative EOF3 (Fig. 4). Thus, one cannot make a simple conclusion that if the jet is stronger, then the vorticity tendency is stronger, and the extratropical response will be stronger in the initial stages. The vorticity tendency depends on the detailed structure of the jet relative to the heating. Among the different basic states in this study, stronger jets that are sharper (negative EOF3) or enhanced to the south of the climatological jet (positive EOF1) generally give rise to stronger vorticity tendency.

As shown in section 5a, the vorticity anomalies, which depicts the Rossby wave and its propagation, is constrained by the stationary wavenumber $K_{s}$. The vorticity anomalies cannot reach regions where there is no real solution for $K_{s}$. In most of the previous studies, when evaluating the MJO extratropical response in the reanalysis, climate models and forecast models, especially for Rossby wave propagation, geopotential height anomalies (or streamfunction anomalies) are used instead of vorticity (Fig. 7). The geopotential height anomalies, which depend on the intensity and shape of the vorticity 
a) EOF1 +1std Day4

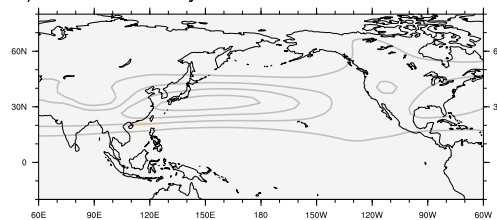

b) EOF1 1 sot 1 std Day8

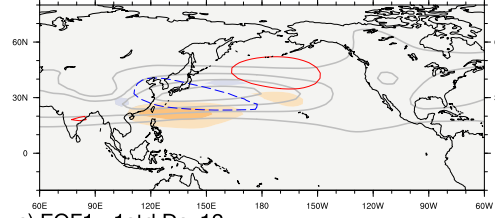

c) EOF1 +1std Day12

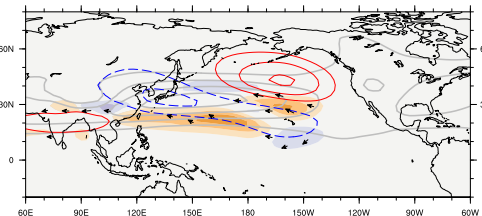

d) EOF EFE $^{\text {of }}+1 \mathrm{std}$ Day 16

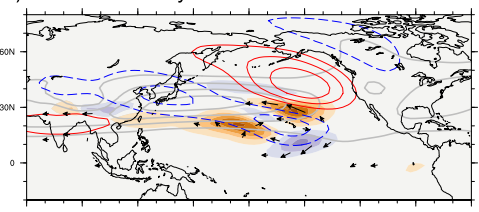

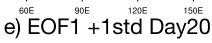

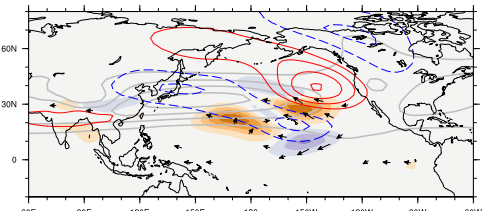

f) $\operatorname{EOF}_{\text {of }}+1$ stdd Day 24

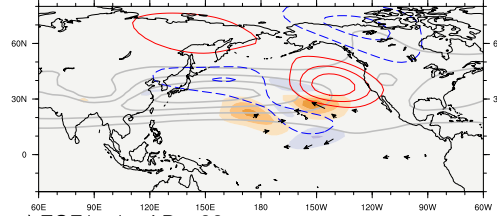

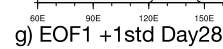

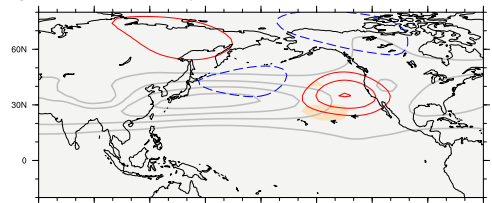

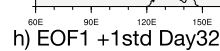

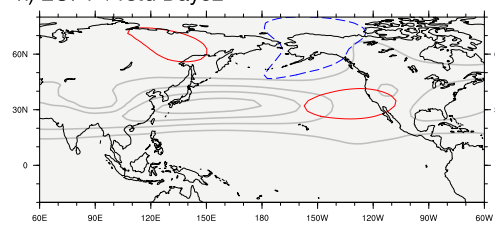

i) Climatology Day4

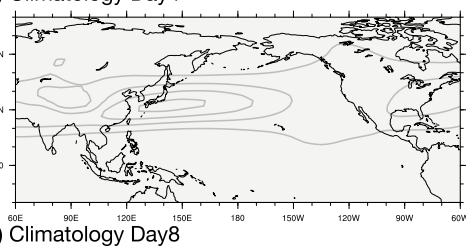

q) EOF1 -1std Day4

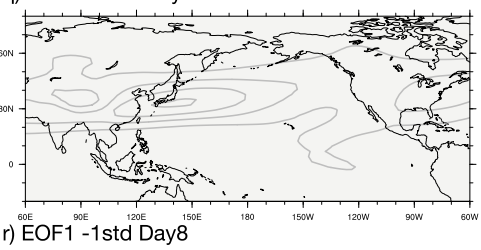

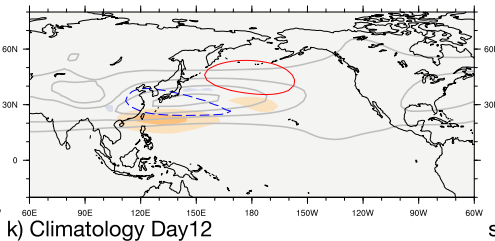
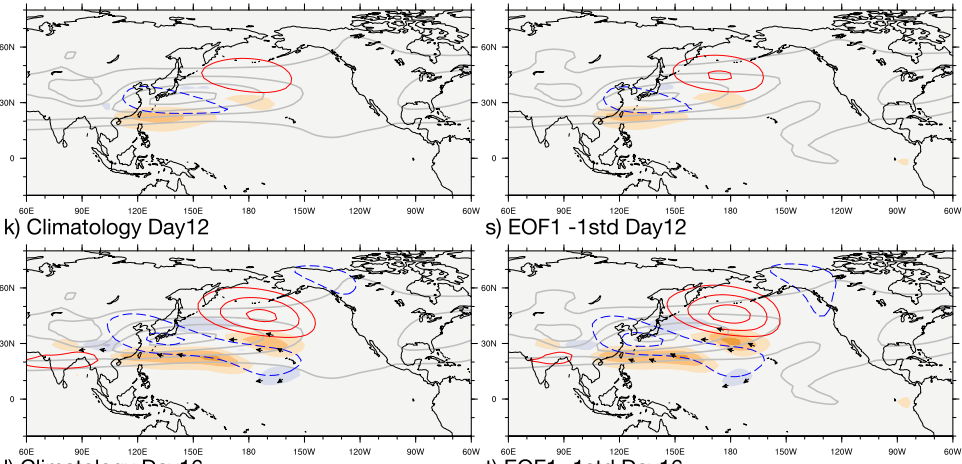

1) Climatology Day16

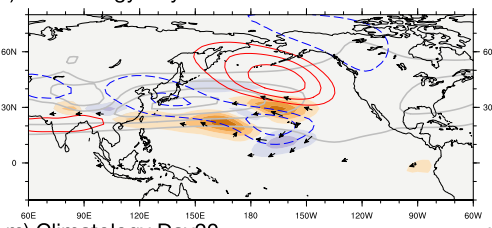

t) EOF1-1std Day16

m) Climatology Day20

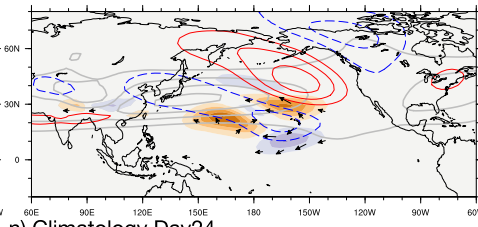

n) Climatology Day24

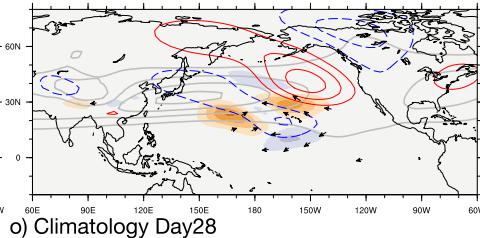

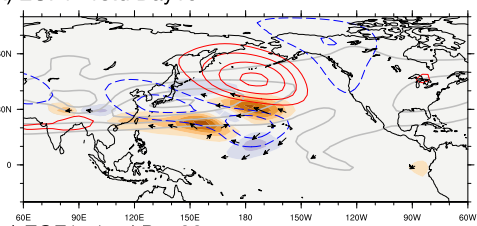

u) EOF1-1 staf Day20

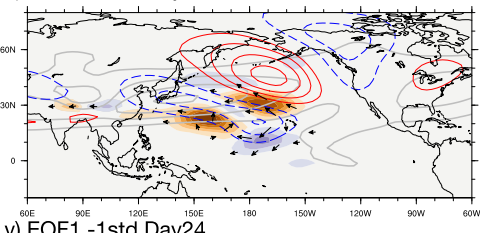

v) EOF1-1std Day24

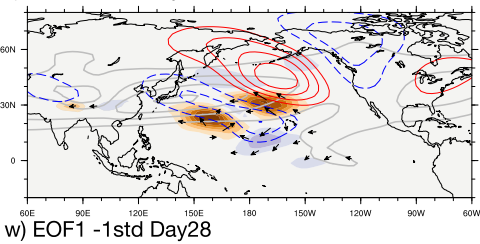

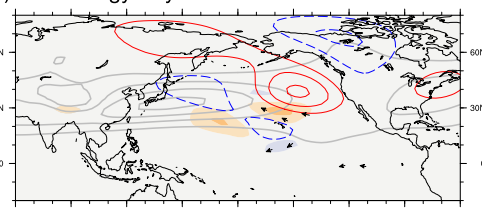

p) Climatology Day32
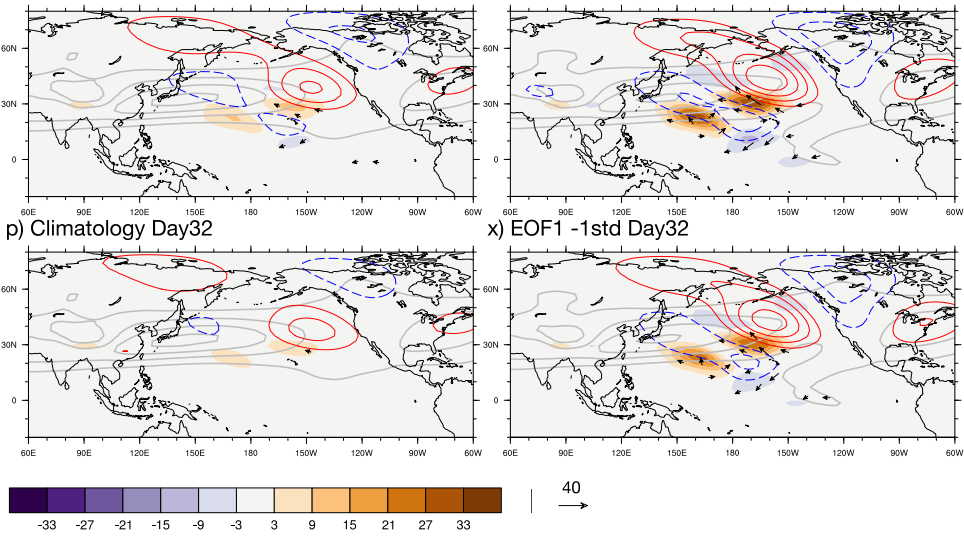

x) EOF1-1std Day32

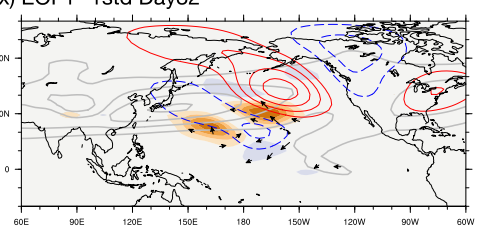

$\stackrel{40}{\longrightarrow}$

FIG. 8. (a) The Rossby wave evolution at day 4 of the PHASE2_15days experiment with the basic state as the +1 standard deviation of EOF1-associated pattern superposed onto climatological background flow. The solid red and dashed blue contours show the geopotential height anomaly at $300 \mathrm{hPa}$; solid red contours are positive, dashed blue contours are negative, and the zero contour is omitted. The contour interval is $10 \mathrm{~m}$. The gray contours show the basic state $300-\mathrm{hPa}$ zonal 
anomalies, can reach broader areas than the vorticity anomalies (Fig. S13 in the online supplemental material) and can extend into regions where $K_{s}$ does not exist (white regions in Fig. S13). Therefore, $K_{s}$ is a very good indicator on where the vorticity anomalies can reach, but it is not perfect to determine where the geopotential height anomalies can reach. However, the distribution of $K_{s}$ is still very useful to explain the main features of the geopotential height anomalies. For negative EOFs 1 , 2 , and 3 in which $K_{s}$ allows the Rossby wave to propagate into Alaska and North America (Fig. 7 and online supplemental Fig. S7), the intensity of the extratropical response over North America is relatively strong (Fig. 3). However, for negative EOF2 (also large-amplitude positive EOF1 cases) in which $K_{s}$ prohibits the Rossby wave propagation into Alaska, the response over North America is relatively weak despite that the extratropical response is very strong over the Pacific (Fig. 3). Thus, if $K_{s}$ blocks the wave path from the Pacific into Alaska, the MJO extratropical response over North America will be limited.

The Rossby waves can be amplified by energy exchange from background flow to anomalous flow (section 5b). Generally, as the energy exchange is proportional to the gradient of the jet, stronger jet will lead to stronger amplification. Especially for the cases when there is strong jet extension (positive EOF1 and negative EOF2), the anomaly associated with the Rossby wave, even if it is not near the large wind gradient region (jet exit) due to the vorticity tendency (Figs. 5 and 6 ) initially, it will be advected into the jet exit region and will be amplified by energy exchange. However, if there is no large jet extension, a stronger jet may not necessarily give rise to stronger energy exchange (e.g., climatological jet and +1 standard deviation of EOF1; see section 5b and Fig. 8). The amplitude of the energy exchange then depends on the location of the vorticity tendency and the gradient of the jet. If initial location of the Rossby waves is already to the east of the jet exit (e.g., climatological background flow in Fig. 7), then not much amplification will happen. Thus, the amplification of the Rossby wave by the background flow, again, depends on the detailed structure of the jet, and the initial location of the Rossby wave response (which also depends on the background flow, and depends on the structure of the MJO heating as well).
The timing and duration of the MJO extratropical response, which can be modulated by the MJO heating, have been systematically explored by Zheng and Chang (2019). In this study, we also find that even if the MJO heating is the same, the timing and duration of the extratropical response can be different for different background flows. For negative EOF1, positive EOF2, and negative EOF3 in which the impact over North America is strong, the wave train is more persistent for negative EOF1 and EOF3, while the Rossby wave decays after day 24 for positive EOF2. For positive EOF1 and negative EOF2 in which there is strong extratropical response over eastern Pacific, the response peaks during day 20 and 24 for positive EOF1, while the peak is from day 24 to 32 for positive EOF2.

As discussed in Moon et al. (2011), the MJO teleconnection (or extratropical impact) can be modulated by El Niño-Southern Oscillation (ENSO). The modulation is not only due to that $\mathrm{MJO}$ can be modulated by ENSO (e.g., Hendon et al. 2007, and many others), but also because the midlatitude jet is modified by ENSO. During El Niño, the Pacific jet is slightly shifted southward and extends eastward toward North America (e.g., Rasmusson and Mo 1993; Straus and Shukla 1997; Quadrelli and Wallace 2002; and many others). The correlation between the Niño-3.4 index and the time series of EOFs 1, 2, and 3, is $0.43,0.27$, and 0.65 , respectively. ENSO-related background states, similar to EOFs of $300-\mathrm{hPa}$ zonal wind, are constructed by using regression onto Niño 3.4 index (see Fig. S14 in the online supplemental material for the $300-\mathrm{hPa}$ zonal wind pattern). Then the REAL_MJO and Phase2_15days experiments are conducted in these background states (Fig. 11). The intensity of the extratropical response over the Pacific and North America in different ENSO states, for both the REAL_MJO and the Phase2_15days experiments, are very similar to that for EOF3 (Figs. 2 and 3 ), as the extratropical response becomes weaker from La Niña to El Niño conditions. Consistent with Henderson and Maloney (2018), the location of the extratropical response over the Pacific moves eastward from La Niña to El Niño conditions, which is very similar to that for EOF1. As EOF1 and EOF3 have relatively high correlations with the Niño-3.4

\footnotetext{
wind. Solid contours are positive, dashed contours are negative, and the zero contour is omitted. The contour interval is $15 \mathrm{~m} \mathrm{~s}^{-1}$. The color shadings show the energy exchange from basic state kinetic energy to eddy kinetic energy $\left(\mathrm{m}^{2} \mathrm{~s}^{-2}\right.$ day $\left.{ }^{-1}\right)$. The arrows are the $\mathbf{E}$ vectors $\left(\mathrm{m}^{2} \mathrm{~s}^{-2}\right)$; only $\mathbf{E}$ vectors larger than $4 \mathrm{~m}^{2} \mathrm{~s}^{-2}$ are plotted. The scaling for the arrows is shown at the bottom of the figure. (b)-(h) As in (a), but for days 8, 12, 16, 20, 24, 28, and 32 respectively. (i)-(p) As in (a)-(h), but the basic state is the climatology of the reanalysis. (q)-(x) As in (a)-(h), but the basic state is -1 standard deviation of the EOF1-associated pattern superposed onto the climatological background flow.
} 
a) EOF2 +1std Day4

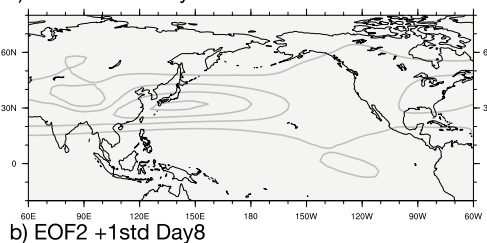

i) Climatology Day4

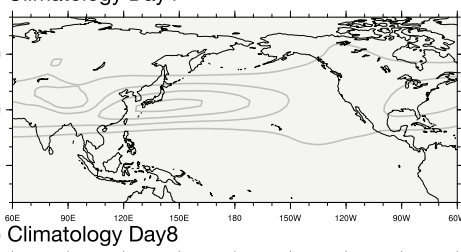

q) EOF2 -1std Day4

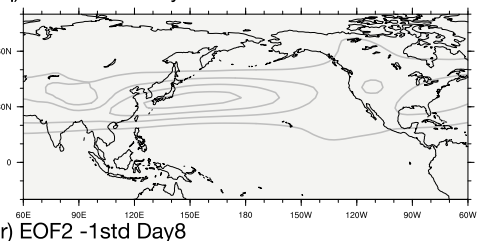

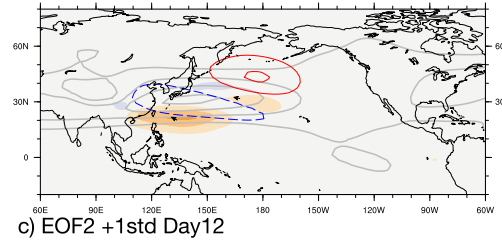
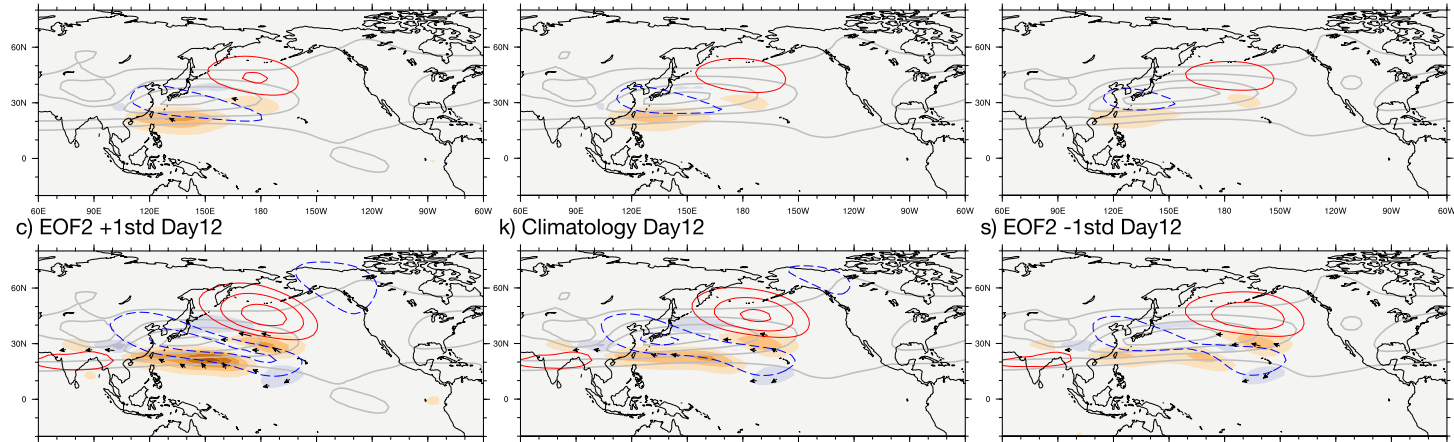

d) $E O F 2+1$ std Day 16

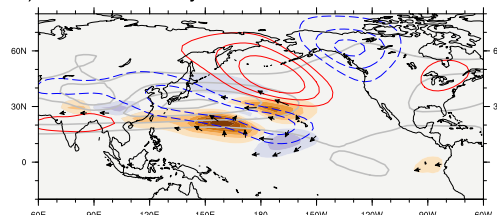

1) Climatology Day16

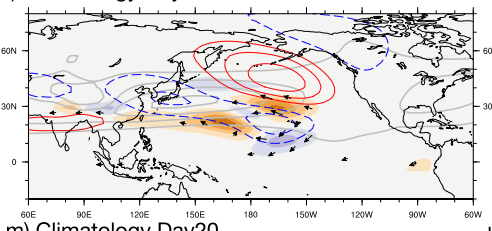

s) EOF2 -1std Day12

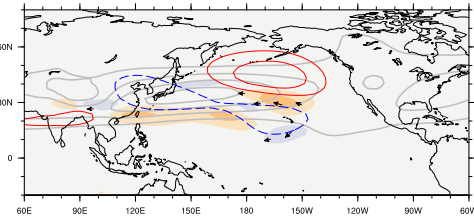

\section{t) EOF2 -1 std Day16}

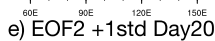

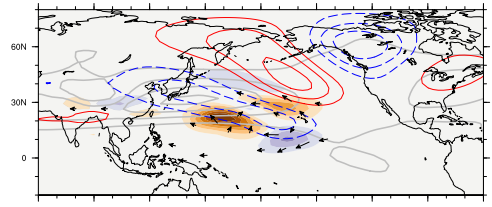

f) $\mathrm{EOF} 2+1$ stdd Day24
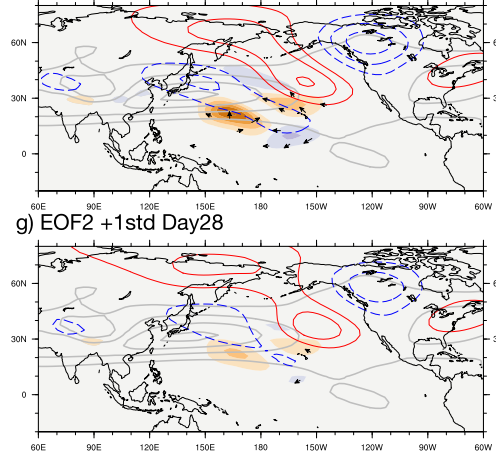

h) EOF2 $^{\text {wot }}+1$ std Day 32

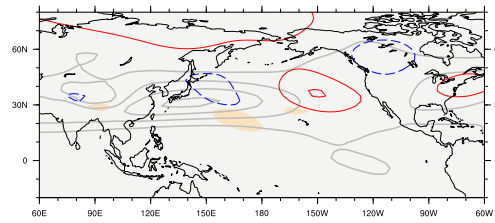

m) Climatology Day 20

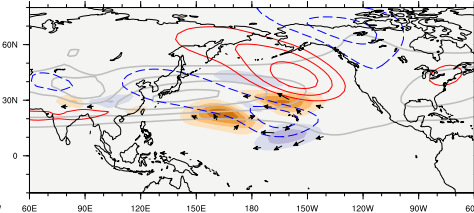

n) Climatology Day24
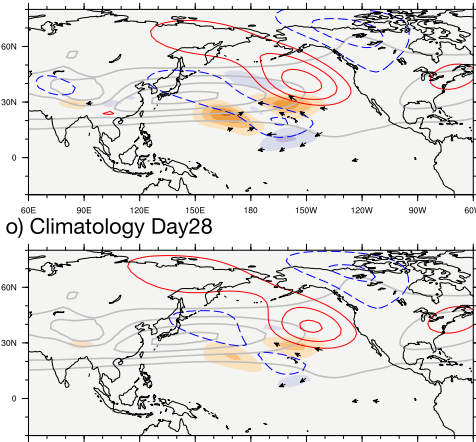

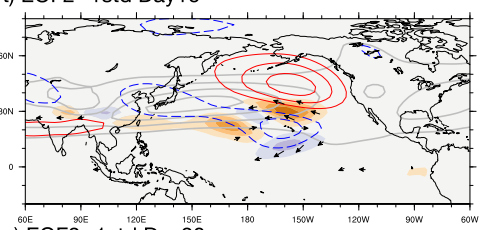

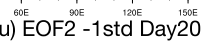

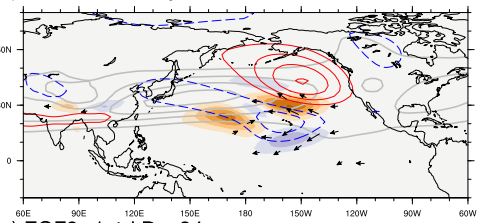

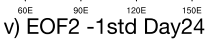

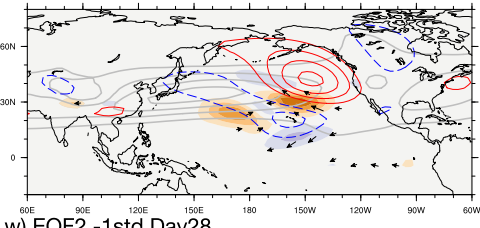

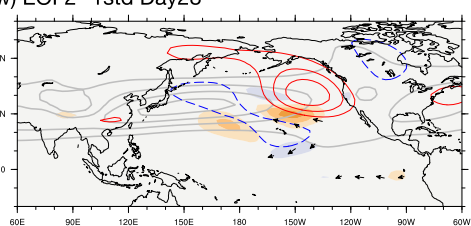

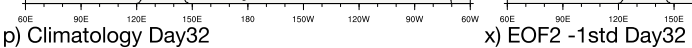
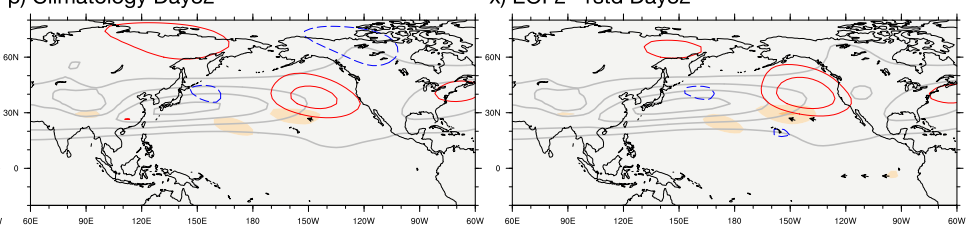

$\stackrel{40}{\longrightarrow}$

FIG. 9. As in Fig. 8, but for the EOF2-associated pattern superposed onto climatological background flow. 
a) EOF3 +1std Day4

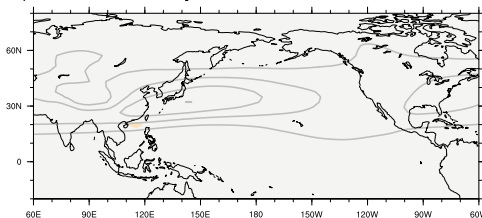

b) $E O F 3^{\text {of }}+1$ std Day8

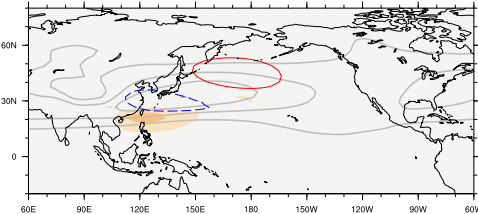

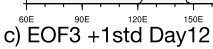

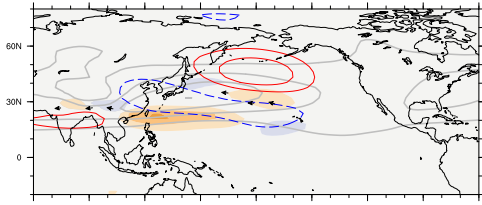

d) $E O F 3+1$ std Day16

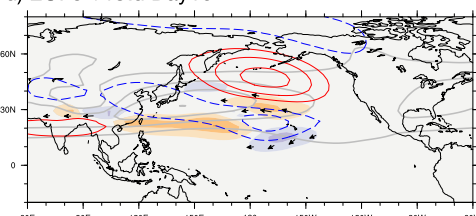

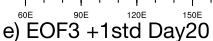

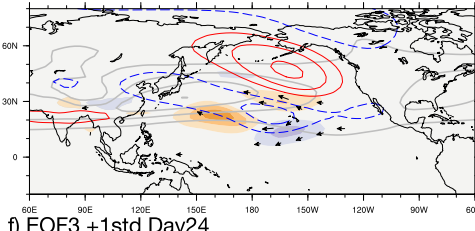

f) EOF $3+1$ std Day 24

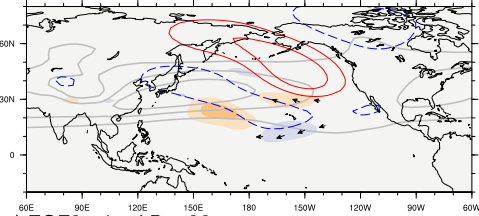

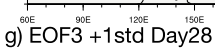

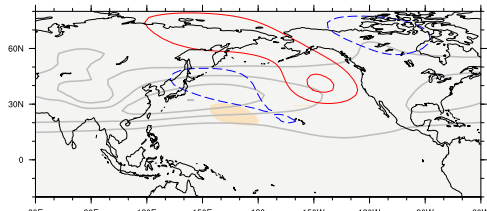

h) EOF3 $^{2}+1$ std Day 32

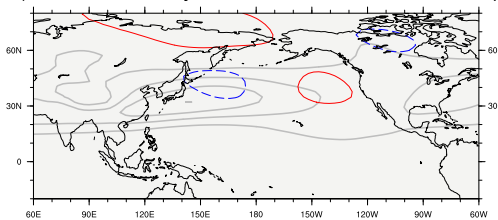

i) Climatology Day4
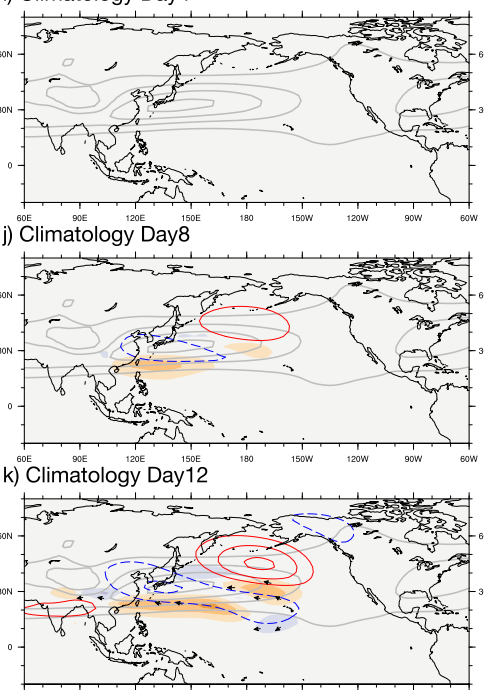

1) Climatology Day16

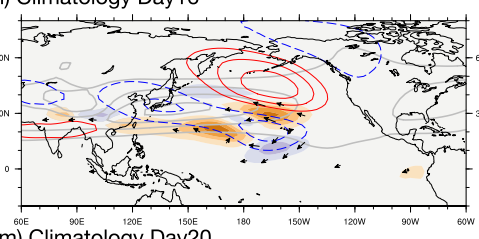

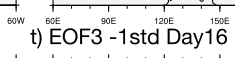

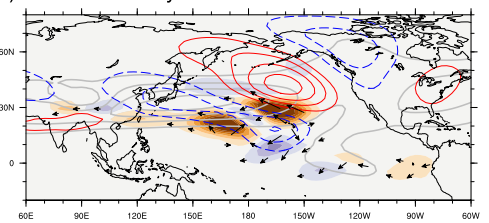

u) EOF3-1 1 std Day20

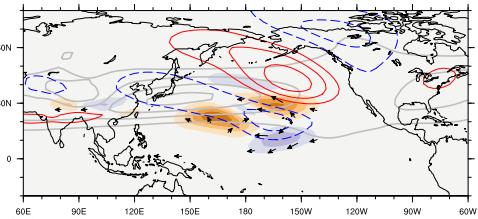

n) Climatology Day24
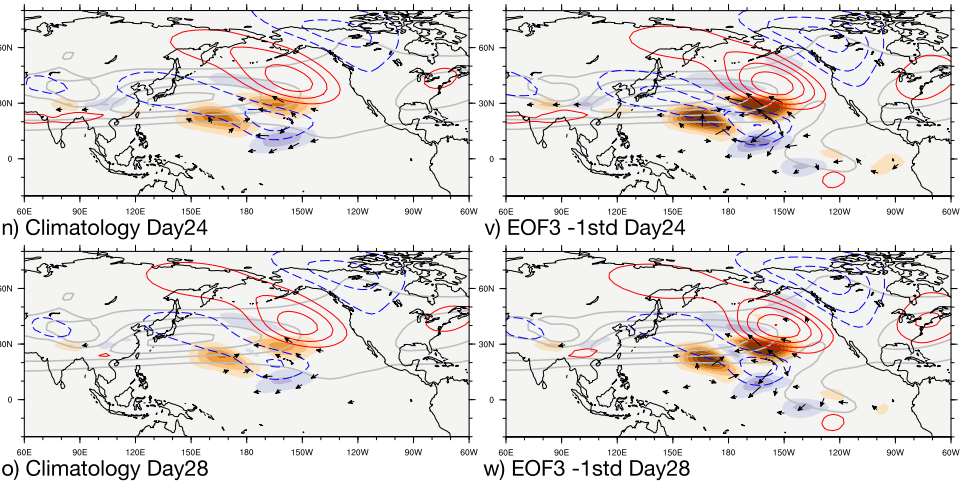

v) vOF $^{\text {on }}-1$ stdd Day24
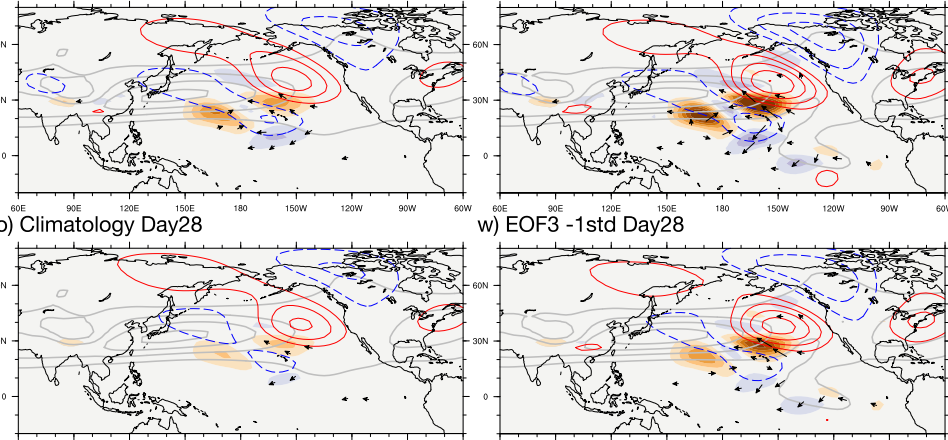

p) Climatology Day32
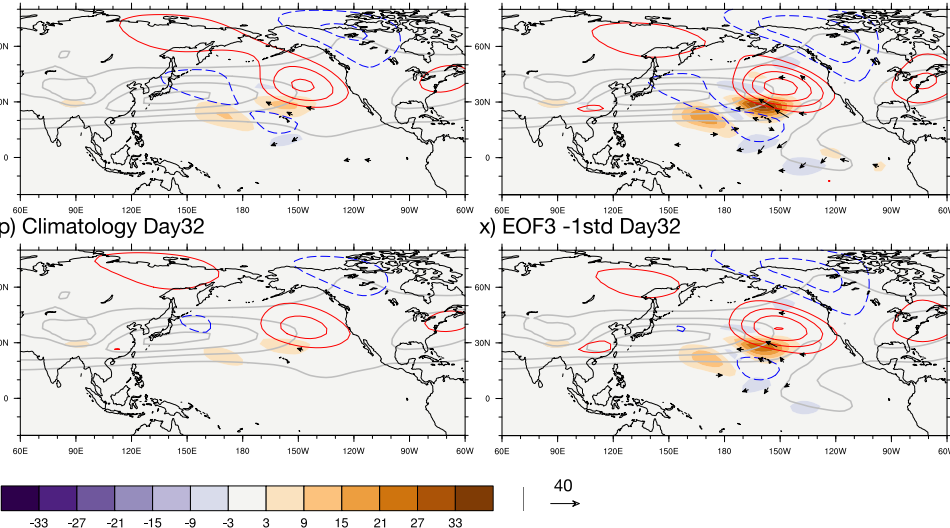

x) EOF3 - 1 std Day32

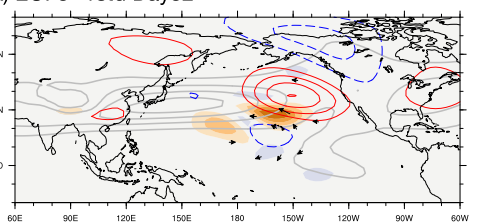

$\stackrel{40}{\longrightarrow}$

Fig. 10. As in Fig. 8, but for the EOF3-associated pattern superposed onto climatological background flow. 


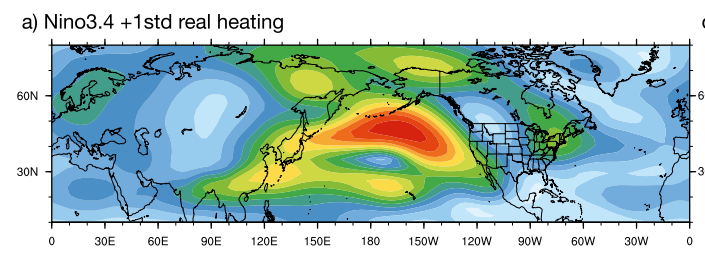

d) Nino3.4 +1std phase2 heating

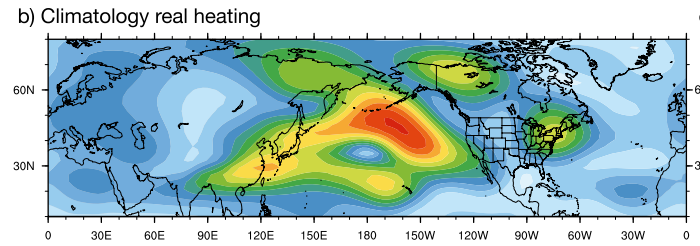

e) Climatology phase2 heating
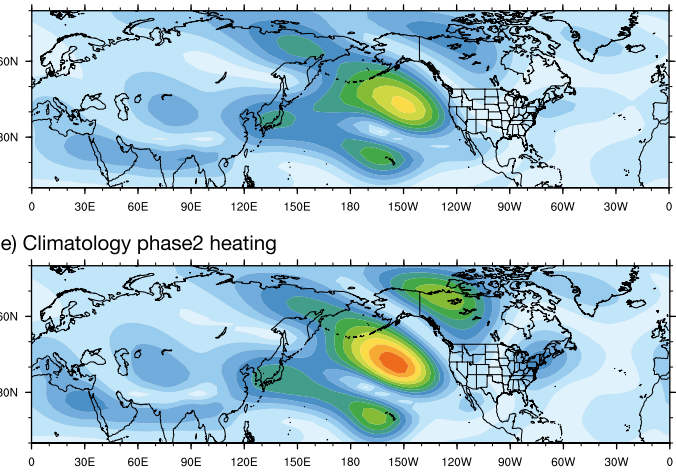

c) Nino3.4 -1std real heating

f) Nino3.4 -1std phase2 heating

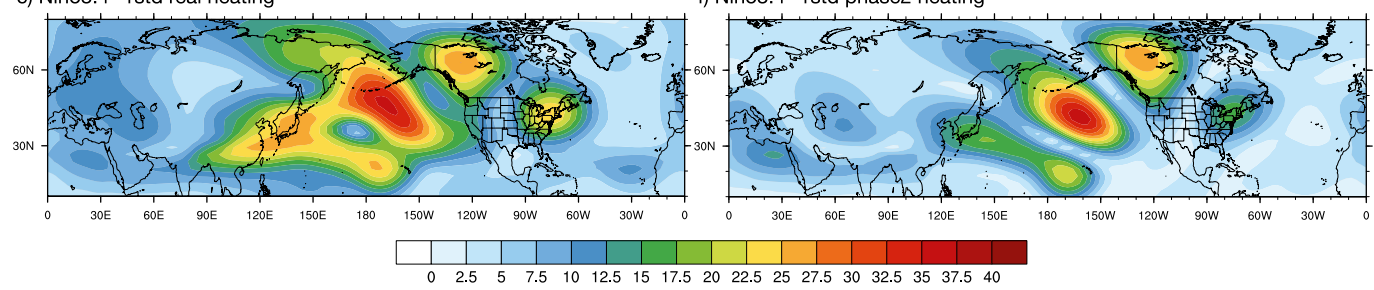

FIG. 11. As in (a)-(c) Fig. 2 and (d)-(f) Fig. 3, but the model basic state is constructed on the basis of regression of the Niño-3.4 index.

index, and the $\mathrm{MJO}$ extratropical response in different ENSO conditions is similar to that in EOF1 and EOF3, the analysis of MJO extratropical response for different EOFs of the jet could provide useful information for understanding the MJO extratropical response in more realistic background state conditions involving combinations of the leading EOFs.

Overall, the MJO extratropical response highly depends on the jet structure. The MJO extratropical response in the vicinity of North America is of more interest as it can have large impacts on human life and economy. When there is jet extension (positive EOF1 and negative EOF2), a strong extratropical response appears over the eastern Pacific, which is due to the amplification by the energy exchange over the jet exit region. This can have significant impact over the west coast of North America. However, the waveguide of the extended jet usually prohibits the wave from propagating into North America. Thus, the strong extratropical response is trapped in the Pacific and can barely reach the interior of North America. To generate strong extratropical response over North America, the waveguide needs to open the pathway for the Rossby wave to propagate into Alaska and east North America. Then the amplitude of the impact will depend on the location and strength of the initial Rossby wave response, as well as the background flow structure, which determines how much energy the anomalous flow can extract from the background flow. Therefore, in terms of subseasonal forecast (week 3-4 forecast), it is crucial to predict the background flow well in order to correctly capture the MJO extratropical response. Johnson et al. (2014) used MJO index and lag composites of observed MJO extratropical response to make week 3-4 prediction by using a statistical model. They found that the MJO does not contribute much skill during weeks $3-4$. On the other hand, Rodney et al. (2013) found skillful prediction at day 15-20 using a multilinear regression model that includes information about the evolution history of the MJO. As we have shown that the MJO extratropical response highly depends on the structure of the jet, lag composite or regression that averages over all background states cannot accurately represent the characteristics of the extratropical response of a specific MJO event. This is consistent with Stan and Krishnamurthy (2019), who showed that adding information about the midlatitudes in the model used by Rodney et al. (2013) can further improve the prediction skill over North America on a subseasonal time scale.

\section{Conclusions}

In this study, the role of background flow in modulating the MJO extratropical response is explored by using a nonlinear baroclinic primitive equation model. The background flow is constructed by using the DJF climatological jet and the first three EOFs of winter monthly zonal wind at $300 \mathrm{hPa}$. Propagating RMM heating, which is similar to observed MJO, as well as stationary RMM phase 2 heating, is imposed onto 

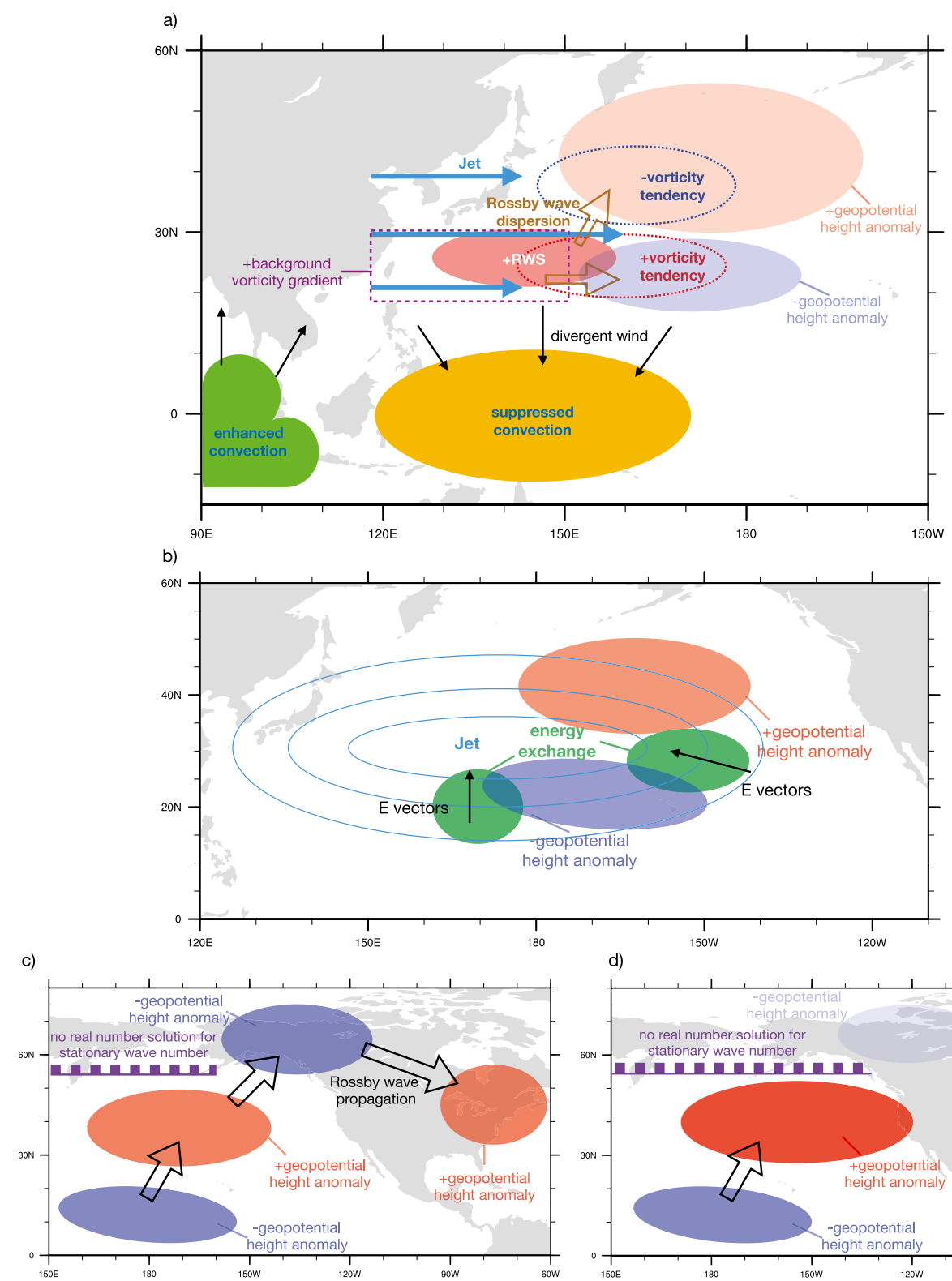

d)

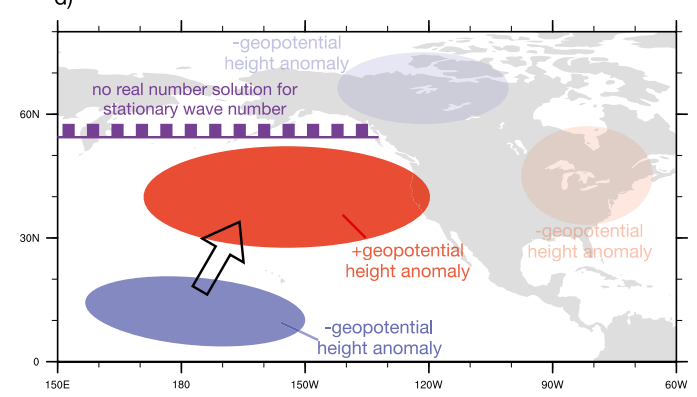

FIG. 12. Schematic figures summarizing the processes related to MJO extratropical response: (a) how MJO gives rise to the Rossby waves, (b) energy exchange from the background flow to anomalous flow, (c) the propagation of the Rossby waves when the waveguide favors the Rossby waves to propagate into North America, and (d) the propagation of the Rossby waves when the waveguide prohibits the Rossby waves from propagating into North America.

the model as external forcing. The location and intensity of the extratropical response in stationary RMM phase 2 heating experiments are consistent with those in the propagating RMM heating experiments. The physical processes linking $\mathrm{MJO}$ heating to extratropical wave trains are summarized in Fig. 12.

As shown in Fig. 12a, the background vorticity gradient is positive poleward over the southern flank of the extratropical jet. The MJO-related divergent wind then gives rise to RWS due to vorticity advection (Seo and
Lee 2017). Rossby wave dispersion gives rise to the negative vorticity anomaly to the north. The vorticity anomalies are then advected eastward by the background flow, which correspond to the geopotential height anomalies over the central Pacific. Stronger jets give rise to larger background vorticity gradient, which will lead to larger RWS generation. However, as the jet is stronger, advection by the rotational wind will also become larger. In the end, a larger RWS does not always give rise to larger local vorticity tendency. The 
tendency depends on the detailed structure of the background flow. The vorticity tendency determines the initial location and strength of the Rossby wave response.

The intensity of the MJO extratropical response depends not only on the RWS or the related vorticity tendency. The anomalous flow can also be amplified due to energy exchange from the background mean kinetic energy into EKE, mainly at the southern flank of the jet and the jet exit region (Fig. 12b). This amplification depends on both the structure of the background flow and the location, shape, and intensity of the anomalous flow. For the jet extension scenario, the gradient of the zonal wind is large over the jet exit region, which leads to strong amplification over the eastern North Pacific. This leads to a large MJO extratropical response over the west coast of North America.

Stationary wavenumber $K_{s}$ determines in which regions stationary Rossby waves can propagate (Figs. 12c,d). When the jet extends into the eastern North Pacific, usually the region where stationary Rossby wave cannot propagate (in the northern flank of the jet) also extends eastward (Fig. 12d). This will block the pathway for the Rossby wave to propagate to the north and east into Alaska and eastern North America. The MJO-induced Rossby wave is then trapped in the Pacific and does not have large impact over North America. When the background zonal wind does not have a large gradient over eastern North Pacific (Fig. 12c), the waveguide allows the wave to propagate into North America. Then the MJO extratropical response can reach North America.

Overall, the location and intensity, as well as the timing and duration, of the MJO extratropical response are highly dependent on the structure of the background flow. Because the MJO extratropical impact is potentially one of the key sources for subseasonal extratropical predictability, to better capture the MJO extratropical response on the subseasonal time scale the forecast model not only needs to capture the MJO evolution, but also needs to capture the basic state of the extratropical jet well.

Acknowledgments. The authors thank three anomalous reviewers for comments that helped to clarify the discussion. This research has been mainly conducted as part of the NOAA MAPP S2S Prediction Task Force and was supported by NOAA Grant NA16OAR4310070.

\section{REFERENCES}

Adames, Á. F., J. Patoux, and R. C. Foster, 2014: The contribution of extratropical waves to the MJO wind field. J. Atmos. Sci., 71, 155-176, https://doi.org/10.1175/JAS-D-13-084.1.

Baxter, S., S. Weaver, J. Gottschalck, and Y. Xue, 2014: Pentad evolution of wintertime impacts of the Madden-Julian oscillation over the contiguous United States. J. Climate, 27, 73567367, https://doi.org/10.1175/JCLI-D-14-00105.1.
Becker, E. J., E. H. Berbery, and R. W. Higgins, 2011: Modulation of cold-season U.S. daily precipitation by the Madden-Julian oscillation. J. Climate, 24, 5157-5166, https://doi.org/10.1175/ 2011JCLI4018.1.

Blackmon, M. L., Y. Lee, J. M. Wallace, and H. Hsu, 1984: Time variation of $500 \mathrm{mb}$ height fluctuations with long, intermediate and short time scales as deduced from lag-correlation statistics. J. Atmos. Sci., 41, 981-991, https://doi.org/10.1175/15200469(1984)041<0981:TVOMHF>2.0.CO;2.

Cassou, C., 2008: Intraseasonal interaction between the MaddenJulian oscillation and the North Atlantic Oscillation. Nature, 455, 523-527, https://doi.org/10.1038/nature07286.

Chang, E. K. M., 1993: Downstream development of baroclinic waves as inferred from regression analysis. J. Atmos. Sci., 50, 2038-2053, https://doi.org/10.1175/1520-0469(1993)050<2038: DDOBWA $>2.0 . \mathrm{CO} ; 2$.

__, 2006: An idealized nonlinear model of the Northern Hemisphere winter storm tracks. J. Atmos. Sci., 63, 18181839, https://doi.org/10.1175/JAS3726.1.

- 2009: Diabatic and orographic forcing of northern winter stationary waves and storm tracks. J. Climate, 22, 670-688, https://doi.org/10.1175/2008JCLI2403.1.

Dee, D. P., and Coauthors, 2011: The ERA-Interim reanalysis: Configuration and performance of the data assimilation system. Quart. J. Roy. Meteor. Soc., 137, 553-597, https://doi.org/ 10.1002/qj.828.

DelSole, T., L. Trenary, M. K. Tippett, and K. Pegion, 2017: Predictability of week-3-4 average temperature and precipitation over the contiguous United States. J. Climate, 30, 34993512, https://doi.org/10.1175/JCLI-D-16-0567.1.

Deng, Y., and T. Jiang, 2011: Intraseasonal modulation of the North Pacific storm track by tropical convection in boreal winter. J. Climate, 24, 1122-1137, https://doi.org/10.1175/2010JCLI3676.1.

Donald, A., H. Meinke, B. Power, A. Maia, M. C. Wheeler, N. White, R. C. Stone, and J. Ribbe, 2006: Near-global impact of the Madden-Julian oscillation on rainfall. Geophys. Res. Lett., 33, L09704, https://doi.org/10.1029/2005GL025155.

Flatau, M., and Y. Kim, 2013: Interaction between the MJO and polar circulations. J. Climate, 26, 3562-3574, https://doi.org/ 10.1175/JCLI-D-11-00508.1.

Goss, M., and S. B. Feldstein, 2015: The impact of the initial flow on the extratropical response to Madden-Julian oscillation convective heating. Mon. Wea. Rev., 143, 1104-1121, https:// doi.org/10.1175/MWR-D-14-00141.1.

Grise, K. M., S. Son, and J. R. Gyakum, 2013: Intraseasonal and interannual variability in North American storm tracks and its relationship to equatorial Pacific variability. Mon. Wea. Rev., 141, 3610-3625, https://doi.org/10.1175/MWR-D-12-00322.1.

Guo, Y., T. Shinoda, J. Lin, and E. K. M. Chang, 2017: Variations of Northern Hemisphere storm track and extratropical cyclone activity associated with the Madden-Julian oscillation. J. Climate, 30, 4799-4818, https://doi.org/10.1175/JCLI-D16-0513.1.

Held, I. M., and M. J. Suarez, 1994: A proposal for the intercomparison of the dynamical cores of atmospheric general circulation models. Bull. Amer. Meteor. Soc., 75, 1825-1830, https://doi.org/10.1175/ 1520-0477(1994)075<1825:APFTIO>2.0.CO;2.

_- M. Ting, and H. Wang, 2002: Northern winter stationary waves: Theory and modeling. J. Climate, 15, 2125-2144, https://doi.org/10.1175/1520-0442(2002)015<2125:NWSWTA > 2.0.CO;2.

Henderson, S. A., and E. D. Maloney, 2018: The impact of the Madden-Julian oscillation on high-latitude winter blocking 
during El Niño-Southern oscillation events. J. Climate, 31, 5293-5318, https://doi.org/10.1175/JCLI-D-17-0721.1.

$\longrightarrow$ - $\longrightarrow$, and S. Son, 2017: Madden-Julian oscillation Pacific teleconnections: The impact of the basic state and MJO representation in general circulation models. J. Climate, 30, 4567-4587, https://doi.org/10.1175/JCLI-D-16-0789.1.

Hendon, H. H., M. C. Wheeler, and C. Zhang, 2007: Seasonal dependence of the MJO-ENSO relationship. J. Climate, 20, 531-543, https://doi.org/10.1175/JCLI4003.1.

Hoskins, B. J., and D. J. Karoly, 1981: The steady linear response of a spherical atmosphere to thermal and orographic forcing. J. Atmos. Sci., 38, 1179-1196, https://doi.org/10.1175/15200469(1981)038<1179:TSLROA > 2.0.CO;2.

— , and T. Ambrizzi, 1993: Rossby wave propagation on a realistic longitudinally varying flow. J. Atmos. Sci., 50, 1661-1671, https:// doi.org/10.1175/1520-0469(1993)050<1661:RWPOAR >2.0.CO;2.

_ I. N. James, and G. H. White, 1983: The shape, propagation and mean-flow interaction of large-scale weather systems. J. Atmos. Sci., 40, 1595-1612, https://doi.org/10.1175/15200469(1983)040<1595:TSPAMF $>2.0$.CO;2.

Hu, W., P. Liu, Q. Zhang, and B. He, 2019: Dominant patterns of winter-time intraseasonal surface air temperature over the CONUS in response to MJO convections. Climate Dyn., 53, 3917-3936, https://doi.org/10.1007/s00382-019-04760-x.

Jin, F., and B. J. Hoskins, 1995: The direct response to tropical heating in a baroclinic atmosphere. J. Atmos. Sci., 52, 307-319, https://doi.org/10.1175/1520-0469(1995)052<0307:TDRTTH > 2.0.CO;2.

Johnson, N. C., D. C. Collins, S. B. Feldstein, M. L. L'Heureux, and E. E. Riddle, 2014: Skillful wintertime North American temperature forecasts out to 4 weeks based on the state of ENSO and the MJO. Wea. Forecasting, 29, 23-38, https://doi.org/ 10.1175/WAF-D-13-00102.1.

Karoly, D., 1983: Rossby wave propagation in a barotropic atmosphere. Dyn. Atmos. Oceans, 7, 111-125, https://doi.org/ 10.1016/0377-0265(83)90013-1.

Kim, H., P. J. Webster, V. E. Toma, and D. Kim, 2014: Predictability and prediction skill of the MJO in two operational forecasting systems. J. Climate, 27, 5364-5378, https://doi.org/10.1175/JCLI-D-13-00480.1.

— , F. Vitart, and D. E. Waliser, 2018: Prediction of the MaddenJulian oscillation: A review. J. Climate, 31, 9425-9443, https:// doi.org/10.1175/JCLI-D-18-0210.1.

Kunkel, K. E., D. R. Easterling, D. A. Kristovich, B. Gleason, L. Stoecker, and R. Smith, 2012: Meteorological causes of the secular variations in observed extreme precipitation events for the conterminous United States. J. Hydrometeor., 13, 1131-1141, https://doi.org/10.1175/JHM-D-11-0108.1.

Lee, Y.-Y., and G.-H. Lim, 2012: Dependency of the North Pacific winter storm tracks on the zonal distribution of MJO convection. J. Geophys. Res., 117, D14101, https://doi.org/10.1029/ 2011JD016417.

L'Heureux, M. L., and R. W. Higgins, 2008: Boreal winter links between the Madden-Julian oscillation and the Arctic Oscillation. J. Climate, 21, 3040-3050, https://doi.org/ 10.1175/2007JCLI1955.1.

Lim, Y., S. Son, and D. Kim, 2018: MJO prediction skill of the subseasonal-to-seasonal prediction models. J. Climate, 31, 4075-4094, https://doi.org/10.1175/JCLI-D-17-0545.1.

Lin, H., and G. Brunet, 2009: The influence of the Madden-Julian oscillation on Canadian wintertime surface air temperature. Mon. Wea. Rev., 137, 2250-2262, https://doi.org/10.1175/ 2009MWR2831.1.
— , and - 2018: Extratropical response to the MJO: Nonlinearity and sensitivity to the initial state. J. Atmos. Sci., 75, 219-234, https://doi.org/10.1175/JAS-D-17-0189.1.

$\longrightarrow,-$, and J. Derome, 2009: An observed connection between the North Atlantic Oscillation and the Madden-Julian oscillation. J. Climate, 22, 364-380, https://doi.org/10.1175/ 2008JCLI2515.1.

- — - and R. Mo, 2010: Impact of the Madden-Julian oscillation on wintertime precipitation in Canada. Mon. Wea. Rev., 138, 3822-3839, https://doi.org/10.1175/2010MWR3363.1.

Lukens, K. E., S. B. Feldstein, C. Yoo, and S. Lee, 2017: The dynamics of the extratropical response to Madden-Julian oscillation convection. Quart. J. Roy. Meteor. Soc., 143, 1095-1106, https://doi.org/10.1002/qj.2993.

Ma, C., and E. K. M. Chang, 2017: Impacts of storm-track variations on wintertime extreme weather events over the continental United States. J. Climate, 30, 4601-4624, https://doi.org/ 10.1175/JCLI-D-16-0560.1.

MacRitchie, K., and P. E. Roundy, 2016: The two-way relationship between the Madden-Julian oscillation and anticyclonic wave breaking. Quart. J. Roy. Meteor. Soc., 142, 2159-2167, https:// doi.org/10.1002/qj.2809.

Madden, R. A., and P. R. Julian, 1971: Detection of a 40-50 day oscillation in the zonal wind in the tropical Pacific. J. Atmos. Sci., 28, 702-708, https://doi.org/10.1175/1520-0469(1971) 028<0702:DOADOI $>2.0 . \mathrm{CO} ; 2$.

_, and - 1972: Description of global-scale circulation cells in the tropics with a 40-50 day period. J. Atmos. Sci., 29, 1109-1123, https://doi.org/10.1175/1520-0469(1972)029<1109: DOGSCC $>2.0 . \mathrm{CO} ; 2$.

—_, and —_, 1994: Observations of the 40-50-day tropical oscillation-A review. Mon. Wea. Rev., 122, 814-837, https://doi.org/10.1175/1520-0493(1994)122<0814:OOTDTO> 2.0.CO;2.

Matthews, A. J., B. J. Hoskins, and M. Masutani, 2004: The global response to tropical heating in the Madden-Julian oscillation during the northern winter. Quart. J. Roy. Meteor. Soc., 130, 1991-2011, https://doi.org/10.1256/qj.02.123.

Moon, J.-Y., B. Wang, and K.-J. Ha, 2011: ENSO regulation of MJO teleconnection. Climate Dyn., 37, 1133-1149, https:// doi.org/10.1007/s00382-010-0902-3.

Moore, R. W., O. Martius, and T. Spengler, 2010: The modulation of the subtropical and extratropical atmosphere in the Pacific basin in response to the Madden-Julian oscillation. Mon. Wea. Rev., 138, 2761-2779, https://doi.org/10.1175/ 2010MWR3194.1.

Mori, M., and M. Watanabe, 2008: The growth and triggering mechanisms of the PNA: A MJO-PNA coherence. J. Meteor. Soc. Japan, 86, 213-236, https://doi.org/10.2151/jmsj.86.213.

North, G. R., T. L. Bell, R. F. Cahalan, and F. J. Moeng, 1982: Sampling errors in the estimation of empirical orthogonal functions. Mon. Wea. Rev., 110, 699-706, https://doi.org/ 10.1175/1520-0493(1982)110<0699:SEITEO > 2.0.CO;2.

Quadrelli, R., and J. M. Wallace, 2002: Dependence of the structure of the Northern Hemisphere annular mode on the polarity of ENSO. Geophys. Res. Lett., 29, 2132, https://doi.org/ 10.1029/2002GL015807.

Rasmusson, E. M., and K. Mo, 1993: Linkages between 200-mb tropical and extratropical circulation anomalies during the 1986-1989 ENSO cycle. J. Climate, 6, 595-616, https://doi.org/ 10.1175/1520-0442(1993)006<0595:LBMTAE $>2.0 . C O ; 2$.

Ray, P., and T. Li, 2013: Relative roles of circumnavigating waves and extratropics on the MJO and its relationship with the 
mean state. J. Atmos. Sci., 70, 876-893, https://doi.org/10.1175/ JAS-D-12-0153.1.

—- C. Zhang, J. Dudhia, and S. S. Chen, 2009: A numerical case study on the initiation of the Madden-Julian oscillation. J. Atmos. Sci., 66, 310-331, https://doi.org/10.1175/ 2008JAS2701.1.

Riddle, E. E., M. B. Stoner, N. C. Johnson, M. L. L'Heureux, D. C. Collins, and S. B. Feldstein, 2013: The impact of the MJO on clusters of wintertime circulation anomalies over the North American region. Climate Dyn., 40, 1749-1766, https://doi.org/ 10.1007/s00382-012-1493-y.

Rodney, M., H. Lin, and J. Derome, 2013: Subseasonal prediction of wintertime North American surface air temperature during strong MJO events. Mon. Wea. Rev., 141, 2897-2909, https:// doi.org/10.1175/MWR-D-12-00221.1.

Sardeshmukh, P. D., and B. J. Hoskins, 1988: The generation of global rotational flow by steady idealized tropical divergence. J. Atmos. Sci., 45, 1228-1251, https://doi.org/10.1175/15200469(1988)045<1228:TGOGRF>2.0.CO;2.

Schreck, C. J., J. M. Cordeira, and D. Margolin, 2013: Which MJO events affect North American temperatures? Mon. Wea. Rev., 141, 3840-3850, https://doi.org/10.1175/MWR-D-13-00118.1.

Seo, K., and S. Son, 2012: The global atmospheric circulation response to tropical diabatic heating associated with the Madden-Julian oscillation during northern winter. J. Atmos. Sci., 69, 79-96, https://doi.org/10.1175/2011JAS3686.1.

, and H. Lee, 2017: Mechanisms for a PNA-like teleconnection pattern in response to the MJO. J. Atmos. Sci., 74, 1767-1781, https://doi.org/10.1175/JAS-D-16-0343.1.

,-- , and D. M. Frierson, 2016: Unraveling the teleconnection mechanisms that induce wintertime temperature anomalies over the Northern Hemisphere continents in response to the MJO. J. Atmos. Sci., 73, 3557-3571, https://doi.org/10.1175/ JAS-D-16-0036.1.

Simmons, A. J., J. M. Wallace, and G. W. Branstator, 1983: Barotropic wave propagation and instability, and atmospheric teleconnection patterns. J. Atmos. Sci., 40, 1363-1392, https://doi.org/10.1175/1520-0469(1983)040<1363:BWPAIA> 2.0.CO;2.

Song, L., and R. Wu, 2019: Combined effects of the MJO and the Arctic Oscillation on the intraseasonal eastern China winter temperature variations. J. Climate, 32, 2295-2311, https:// doi.org/10.1175/JCLI-D-18-0625.1.

Stan, C., and V. Krishnamurthy, 2019: Intra-seasonal and seasonal variability of the Northern Hemisphere extra-tropics. Climate Dyn., 53, 4821-4839, https://doi.org/10.1007/s00382019-04827-9.

Straus, D. M., and J. Shukla, 1997: Variations of midlatitude transient dynamics associated with ENSO. J. Atmos. Sci., 54, 777-790, https://doi.org/10.1175/1520-0469(1997)054<0777:VOMTDA> 2.0.CO;2.

Tian, D., E. F. Wood, and X. Yuan, 2017: CFSv2-based subseasonal precipitation and temperature forecast skill over the contiguous United States. Hydrol. Earth Syst. Sci., 21, 14771490, https://doi.org/10.5194/hess-21-1477-2017.

Ting, M., and P. D. Sardeshmukh, 1993: Factors determining the extratropical response to equatorial diabatic heating anomalies. J. Atmos. Sci., 50, 907-918, https://doi.org/10.1175/15200469(1993)050<0907:FDTERT>2.0.CO;2.

Tseng, K.-C., E. A. Barnes, and E. D. Maloney, 2018: Prediction of the midlatitude response to strong Madden-Julian oscillation events on S2S time scales. Geophys. Res. Lett., 45, 463-470, https://doi.org/10.1002/2017GL075734.
— E. Maloney, and E. Barnes, 2019: The consistency of MJO teleconnection patterns: An explanation using linear Rossby wave theory. J. Climate, 32, 531-548, https://doi.org/10.1175/ JCLI-D-18-0211.1.

Vecchi, G. A., and N. A. Bond, 2004: The Madden-Julian Oscillation (MJO) and northern high latitude wintertime surface air temperatures. Geophys. Res. Lett., 31, L04104, https://doi.org/10.1029/2003GL018645.

Vitart, F., 2017: Madden-Julian oscillation prediction and teleconnections in the S2S database. Quart. J. Roy. Meteor. Soc., 143, 2210-2220, https://doi.org/10.1002/qj.3079.

Waliser, D., and Coauthors, 2009: MJO simulation diagnostics. J. Climate, 22, 3006-3030, https://doi.org/10.1175/2008JCLI2731.1.

Wang, H., and M. Ting, 1999: Seasonal cycle of the climatological stationary waves in the NCEP-NCAR reanalysis. J. Atmos. Sci., 56, 3892-3919, https://doi.org/10.1175/1520-0469(1999) $056<3892$ :SCOTCS $>2.0$.CO; 2 .

Wheeler, M. C., and H. H. Hendon, 2004: An all-season real-time multivariate MJO index: Development of an index for monitoring and prediction. Mon. Wea. Rev., 132, 1917-1932, https://doi.org/ 10.1175/1520-0493(2004)132<1917:AARMMI>2.0.CO;2.

Xia, X., and E. K. Chang, 2014: Diabatic damping of zonal index variations. J. Atmos. Sci., 71, 3090-3105, https://doi.org/10.1175/ JAS-D-13-0292.1.

Xiang, B., M. Zhao, X. Jiang, S. Lin, T. Li, X. Fu, and G. Vecchi, 2015: The 3-4-week MJO prediction skill in a GFDL coupled model. J. Climate, 28, 5351-5364, https://doi.org/10.1175/JCLID-15-0102.1.

— S. J. Lin, M. Zhao, N. C. Johnson, X. Yang, and X. Jiang, 2019: Subseasonal week 3-5 surface air temperature prediction during boreal wintertime in a GFDL model. Geophys. Res. Lett., 46, 416-425, https://doi.org/10.1029/2018GL081314.

Yadav, P., and D. M. Straus, 2017: Circulation response to fast and slow MJO episodes. Mon. Wea. Rev., 145, 1577-1596, https:// doi.org/10.1175/MWR-D-16-0352.1.

Yang, X., and E. K. M. Chang, 2006: Variability of the Southern Hemisphere winter split flow-A case of two-way reinforcement between mean flow and eddy anomalies. J. Atmos. Sci., 63, 634-650, https://doi.org/10.1175/JAS3643.1.

Yoo, C., S. Feldstein, and S. Lee, 2011: The impact of the MaddenJulian oscillation trend on the Arctic amplification of surface air temperature during the 1979-2008 boreal winter. Geophys. Res. Lett., 38, L24804, https://doi.org/10.1029/2011GL049881.

Zhao, C., T. Li, and T. Zhou, 2013: Precursor signals and processes associated with MJO initiation over the tropical Indian ocean. J. Climate, 26, 291-307, https://doi.org/10.1175/JCLI-D-1200113.1.

Zheng, C., and E. K. M. Chang, 2019: The role of MJO propagation, lifetime, and intensity on modulating the temporal evolution of the MJO extratropical response. J. Geophys. Res., 124, 5352-5378, https://doi.org/10.1029/2019JD030258.

, - , H. Kim, M. Zhang, and W. Wang, 2018: Impacts of the Madden-Julian oscillation on storm-track activity, surface air temperature, and precipitation over North America. J. Climate, 31, 6113-6134, https://doi.org/10.1175/JCLI-D-17-0534.1.

Zhou, S., and A. J. Miller, 2005: The interaction of the MaddenJulian oscillation and the Arctic Oscillation. J. Climate, 18, 143-159, https://doi.org/10.1175/JCLI3251.1.

—, M. L'Heureux, S. Weaver, and A. Kumar, 2012: A composite study of the MJO influence on the surface air temperature and precipitation over the continental United States. Climate Dyn., 38, 1459-1471, https://doi.org/10.1007/s00382-011-1001-9. 